\title{
Combined production of biogas and ethanol at high solids loading from wheat straw impregnated with acetic acid: experimental study and techno-economic evaluation
}

\author{
Elisabeth Joelsson, Dora Dienes, Krisztina Kovacs ${ }^{*}$, Mats Galbe and Ola Wallberg
}

\begin{abstract}
Background: Production of ethanol and biogas from acetic acid-impregnated steam-pretreated wheat straw was investigated. The solid fraction after pretreatment was used at high solids concentrations to generate ethanol by simultaneous saccharification and fermentation (SSF). The residual streams were evaluated with regard to biogas production. The experimental results were used to perform a techno-economic evaluation of a biorefinery concerning ethanol, raw biogas, pellet, and electricity production at various solid contents and residence times in the fermentation step. The configurations were also altered to include biogas upgrading to vehicle fuel quality or fermentation of xylose to ethanol.
\end{abstract}

Results: At a water-insoluble solids (WIS) content in the SSF of between 10 and $20 \%$, the ethanol yields exceeded $80 \%$, the highest being $86 \%$ at $12.5 \%$ WIS, expressed as \% of the theoretical maximum, based on the glucan content in SSF. Anaerobic digestion of wheat straw hydrolysate and stillage yielded 4.8 and 1.0-1.2 g methane/100 g dry straw, respectively, in 7-day experiments. Maximum recovery of overall product was achieved when SSF was run at between 10 and $15 \%$ initial WIS content, for which the product yields from $100 \mathrm{~g}$ dry wheat straw were 16.1-16.3 g ethanol, 5.8-6.0 g methane, and $25 \mathrm{~g}$ lignin-rich solid residue. The net present value (NPV) was negative at discount rate of $11 \%$ but positive at $5 \%$ discount rate for all configurations. The $20 \%$ WIS configuration with a residence time of $96 \mathrm{~h}$ in the fermentation stage attained the highest NPV. The minimum ethanol selling price varied between 0.72 and 0.87 EUR/L ethanol when the biogas was unchanged and it decreased to between 0.46 and $0.60 \mathrm{EUR} / \mathrm{L}$ ethanol when the biogas was upgraded to vehicle fuel quality or when xylose was converted to ethanol.

Conclusions: According to the techno-economic assessment, a process that is based on the fermentation of only hexoses to ethanol, and production of raw biogas from xylose is not profitable under the economic assumptions including $11 \%$ discount rate in the evaluation. However, the profitability of a plant can be improved by biogas upgrading to vehicle fuel quality or fermentation of xylose to ethanol.

Keywords: Acetic acid, Wheat straw, Steam pretreatment, Ethanol, Biogas, Simultaneous saccharification and fermentation (SSF), Techno-economic evaluation, High water-insoluble solids (WIS) concentration

${ }^{*}$ Correspondence: Krisztina.Kovacs@chemeng.lth.se

Department of Chemical Engineering, Lund University, P.O. Box 124, 221

00 Lund, Sweden 


\section{Background}

Wheat straw is a low-cost agricultural residue that is a suitable feedstock for second-generation biofuel production, based on its significant availability. It is the preferred raw material for Beta Renewables's commercial plant in Crescentino, Italy, which was the first full-scale plant that converted lignocellulosic biomass into ethanol.

Wheat straw comprises 30-40 \% cellulose, 20-25\% hemicellulose primarily xylan and 20-25 \% lignin [1]. Glucose, generated from the hydrolysis of cellulose, can be converted efficiently to ethanol by Saccharomyces cerevisiae, the most widely used yeast and the most robust fermenting organism. However, wild-type S. cerevisiae strains are unable to metabolize pentoses (C5 sugars), rendering the utilization of pentoses a significant challenge in biomass-to-ethanol conversion. Considerable research has been devoted to developing genetically modified organisms that co-ferment C6 sugars (hexoses) and C5 sugars to ethanol at high yields [2-6], which has led to commercial-scale co-fermentation being implemented at Poet-DSM's cellulosic ethanol plant in Emmetsburg, Iowa, and the Beta Renewables plant in Crescentino.

An alternative method of using pentoses, instead of producing ethanol, is biogas production. Biogas consists primarily of methane and carbon dioxide and can be generated by anaerobic digestion (AD) of a wide range of organic compounds, such as the organic fraction of municipal solid waste, sewage sludge, industrial wastewater, fruit and vegetable waste, aquatic biomass, and lignocelluloses [7]. Most compounds in lignocellulosic biomass can be degraded to biogas, but the $\mathrm{AD}$ of aromatic compounds, such as lignin, is generally believed to be difficult $[8,9]$. The degradability of lignin, however, can be enhanced by pretreatment, leading to depolymerisation reactions, which result in increased availability of lignin to microorganisms [10].

The concept of a biorefinery that combines the production of various biofuels (such as ethanol, biogas, hydrogen, and solid fuel), chemicals, and heat or electricity has recently attracted much interest [11-14]. By using whole lignocellulosic material and producing several products, a biorefinery gains many economic and environmental advantages, based on its minimal use of fossil energy sources and maximum utilization of process streams [12]. Lignocellulose-based ethanol fermentation produces a large fraction of liquid waste stream i.e. stillage which is a potentially significant pollutant. Thus, the use of stillage in biofuel production is an attractive approach. Biogas production from stillage generated from ethanol production using wheat straw has been suggested to provide additional energy to the process and improve the economics of a bioethanol plant [15].
For raw materials with a high content of C5 sugars, such as wheat straw, separating the $\mathrm{C} 5$ stream from the C6 fraction to produce biogas from the $\mathrm{C} 5$ stream and stillage is a notable process concept. This was applied at Inbicon's demonstration plant, in which wheat straw was converted to bioethanol, lignin pellets, and C5 molasses. C5 molasses, originating from the liquid fraction after pretreatment and part of the liquid residue after distillation of ethanol from the fermentation broth (i.e., thin stillage), proved to be a suitable biogas booster in a Danish biogas plant [13].

In the production of bioethanol, wheat straw, as all lignocellulosic biomass, requires pretreatment prior to enzymatic hydrolysis and fermentation to improve the accessibility of cellulose to hydrolytic enzymes. Pretreatment is also beneficial for methane production, as it improves the initial production rate $[10,16]$ and methane yield $[10,17]$. Steam pretreatment, also known as steam explosion, is one of the most efficient methods for processing lignocellulosic biomass and has been used successfully for wheat straw $[1,17,18]$. In most of these studies, sulfur dioxide or sulfuric acid were used as acid catalysts in the steam pretreatment. The main drawback of using sulfur-containing compounds is that they impede the downstream process and must be removed or recycled as acid or $\mathrm{SO}_{2}$.

Acetic acid has been suggested as an alternative to sulfur-containing acids in the steam pretreatment of corn stover [19]. The benefits of acetic acid are that it exists naturally in the hemicellulose of agricultural residues, can be used for biogas production, and lowers the concentrations of inhibitors during steam pretreatment. One disadvantage of using acetic acid for impregnation prior to steam pretreatment is that at high concentrations, it becomes toxic during fermentation [19]. However, this problem can be solved by separating the pretreatment liquid that contains acetic acid from the solids that are to be fermented to ethanol.

A currently popular trend is to perform enzymatic hydrolysis and ethanol fermentation at a high solids content, which increases product concentrations while lowering water input and energy requirements for distillation, thus reducing costs. However, increasing the solids content creates several practical issues, such as mass transfer limitations and a greater concentration of inhibitors, which can offset the cost savings. The challenges of and the outlook on lignocellulosic ethanol production at high solids concentrations have recently been reviewed [20].

Many technological and economic studies on various biorefinery concepts, including ethanol production from lignocellulosic materials, have been reported in the past several years. A variety of raw materials, which require 
different process configurations, have been examined, including bagasse and sugar cane [21, 22], switch grass [23, 24], wood [25-27], and corn and corn stover [2830]. However, to the best of the authors' knowledge, there are few reports on the technical and economic aspects of wheat straw biorefineries.

Most such studies have dealt primarily with mass and energy balances for ethanol production from wheat straw, focusing on heat integration, exergy analysis [31, 32], and downstream processing steps, such as the various alternatives for treating stillage [33]. Ekman et al. [34] performed a techno-economic evaluation of several plant sizes during ethanol production from straw at $10 \%$ WIS content in the fermentation. Kravanja et al. [35] conducted a similar analysis of various configurations of $\mathrm{SO}_{2}$-impregnated, steam-pretreated wheat straw at $10-20 \%$ WIS in the fermentation stage for a plant located in Austria.

Ethanol production at a high solids content ( $35.5 \%$ dry matter, DM) and subsequent $\mathrm{AD}$ of whole stillage has been examined using unwashed steam-pretreated corn stover as raw material [36]. We have performed a similar study using wheat straw as raw material-instead using acetic acid to impregnate the wheat straw prior to pretreatment and separated the process streams to liquid and solid streams after pretreatment. The production of ethanol from the solid fraction of the pretreated straw at high initial solids concentrations (10-20\% WIS) was evaluated by simultaneous saccharification and fermentation (SSF). Then, the utilization of the pretreatment liquid fraction (hydrolysate) and thin stillage was assessed with regard to biogas production.

The advantage of separating the liquid stream from solids after pretreatment was that SSF could be run at a higher solids content without a high concentration of inhibitors. The lignin-rich solid residue that was obtained after SSF, although it was not used in this study, is well suited for the production of pellets and the generation of steam and electricity in a plant.

We performed techno-economic evaluations to analyze the results of the experimental component of the study. Configurations were established using the flow sheet simulation program Aspen Plus, based on the solids content in the SSF. The process configurations included the production of biogas, pellets, and electricity. Plant feasibility was then examined under the various configurations by calculating net present value (NPV) and minimum ethanol selling price (MESP). Sensitivity analysis was conducted for biogas price, discount rate, and corporate taxation. The process was also modified by upgrading the biogas to vehicle fuel quality and fermenting xylose to ethanol.

\section{Results and discussion Experimental part Pretreatment}

Steam pretreatment of acetic acid-impregnated wheat straw was performed at 190,200 , and $210{ }^{\circ} \mathrm{C}$ for $10 \mathrm{~min}$. The water-insoluble solids (WIS) content of the pretreated materials was between 8.1 and $9.7 \%$, and the recovery of WIS was similar in all 3 cases, ranging from 54.9 to $59.6 \%$ (Table 1). Most of the glucan remained in the WIS, and total glucan recoveries exceeded $100 \%$, possibly due to our underestimation of the glucan content in the raw material, as reported by other authors as well $[18,19]$. However, total xylan recovery was sensitive to temperatures above $190{ }^{\circ} \mathrm{C}$, as $96 \%$ of xylan in the raw material was recovered after pretreatment at $190{ }^{\circ} \mathrm{C}$, declining to 60.5 and $39.8 \%$, at 200 and $210{ }^{\circ} \mathrm{C}$, respectively.

As expected, the concentrations of the pentose-degradation products furfural and formic acid and that of acetic acid in the hydrolysate increased, whereas the concentration of xylan in the WIS and the total amounts of xylose monomers and oligomers in the hydrolysate decreased with increasing temperature (Table 2). The glucan and total lignin content in the WIS ranged from $54.2-57.2$ and $32.7-37.7 \%$, respectively.

\section{Simultaneous saccharification and fermentation}

Final ethanol concentrations and yields measured in the SSF are summarized in Table 3. Notably, at $10 \%$ WIS, ethanol concentrations and yields were significantly lower with the material that was pretreated at $190{ }^{\circ} \mathrm{C}$ compared with 200 and $210{ }^{\circ} \mathrm{C}$. One explanation is that the pretreatment at $190{ }^{\circ} \mathrm{C}$ was too mild, and thus, the solid fraction of the pretreated material contained considerably more xylan, resulting in decreased

Table 1 Recovery of WIS, glucan, and xylan after steam pretreatment

\begin{tabular}{llll}
\hline Pretreatment temperature & $\mathbf{1 9 0}^{\mathbf{}} \mathbf{C}$ & $\mathbf{2 0 0}^{\mathbf{}} \mathbf{C}$ & $\mathbf{2 1 0}^{\mathbf{}} \mathbf{C}$ \\
\hline WIS of pretreated material (\%) & 8.1 & 9.7 & 8.3 \\
Recovery (\%) & & & \\
WIS & 59.6 & 59.0 & 54.9 \\
Glucan in WIS & 99.3 & 102.8 & 96.0 \\
Glucan in hydrolysate & 3.8 & 4.0 & 5.3 \\
Total glucan recovery & 103.1 & 106.8 & 101.3 \\
Xylan in WIS & 25.7 & 14.4 & 7.7 \\
Xylan in hydrolysate & 70.2 & 46.1 & 32.1 \\
Total xylan recovery & 96.0 & 60.5 & 39.8 \\
\hline
\end{tabular}

Recoveries are expressed as \% of the amount available in the raw material. The analyses were performed in duplicates, and the relative standard deviations were maximum $6 \%$ 
Table 2 Composition of the WIS fraction and hydrolysate of the pretreated materials

\begin{tabular}{lrrr}
\hline Pretreatment temperature & $\mathbf{1 9 0}{ }^{\circ} \mathbf{C}$ & $\mathbf{2 0 0}{ }^{\circ} \mathbf{C}$ & $\mathbf{2 1 0}{ }^{\circ} \mathbf{C}$ \\
\hline Composition of WIS (\%) & & & \\
Glucan & 54.5 & 57.0 & 57.2 \\
Xylan & 10.1 & 5.7 & 3.3 \\
Arabinan & 0.6 & 1.7 & 0.0 \\
Ash & 2.1 & 1.9 & 1.9 \\
AlL & 29.5 & 30.6 & 34.3 \\
ASL & 3.2 & 3.1 & 3.4 \\
Composition of hydrolysate (g/L) & & & \\
Byproducts, degradation products & & & \\
$\quad$ Formic acid & 0.8 & 1.4 & 1.7 \\
$\quad$ Acetic acid & 2.8 & 6.7 & 6.6 \\
$\quad$ Furfural & 0.8 & 3.1 & 4.8 \\
Sugar monomers & & & \\
$\quad$ Glucose & 0.6 & 0.9 & 1.6 \\
$\quad$ Xylose & 3.8 & 9.1 & 7.9 \\
Arabinose & 2.5 & 2.1 & 1.6 \\
Sugar oligomers & & & \\
Glucose & & 1.7 & 1.6 \\
Xylose & 1.5 & 13.3 & 6.2 \\
Arabinose & 23.7 & 0.3 & 0.0 \\
\hline
\end{tabular}

The analyses were performed in duplicates, and the relative standard deviations were maximum $6 \%$

hydrolyzability and, consequently, lower ethanol yields. Although the pretreatment at $210{ }^{\circ} \mathrm{C}$ effected the highest ethanol concentration and yield, it proved to be too harsh, because little xylan was recovered (Table 1). Thus, to determine the effects of increasing WIS content on ethanol yields by SSF, wheat straw that was pretreated at $200{ }^{\circ} \mathrm{C}$ was chosen as the starting material. At WIS contents higher than $10 \%$, SSF experiments with a 24-h prehydrolysis step (PSSF) were also performed to liquefy the material before the fermentation step.

Ethanol yields, expressed as \% of the theoretical maximum, based on the glucan content in the SSF, were between 83 and $86 \%$ when the material that was pretreated at $200{ }^{\circ} \mathrm{C}$ was used in the SSF at initial WIS contents of between 10 and $20 \%$ (Table 3). Final ethanol concentrations in the fermentation broth ranged from $30.5 \mathrm{~g} / \mathrm{L}$ at $10 \%$ WIS to $67.3 \mathrm{~g} / \mathrm{L}$ at $20 \%$ WIS, and ethanol yields were 15.9-16.3/100 g dry wheat straw.

At the start of SSF, mixing became more and more difficult with increasing WIS contents. At lower initial WIS contents, complete mixing was achieved after maximum $24 \mathrm{~h}$, while at $20 \%$ WIS, the fermentation broth became homogeneous only after $72 \mathrm{~h}$. Therefore, to obtain an ethanol yield of above $80 \%$, the residence time in the SSF at $20 \%$ WIS was increased to $192 \mathrm{~h}$, whereas all other experiments proceeded for $96 \mathrm{~h}$. However, a residence time of up to $192 \mathrm{~h}$ is unlikely to be feasible on an industrial scale, and thus, even though a PSSF at $20 \%$ WIS does not result in the same high yield as SSF at $20 \%$ WIS, introducing a prehydrolysis step and performing SSF in fed-batch mode could be considered at very high solids concentrations to reduce fermentation times significantly.

SSF resulted in higher ethanol concentrations and yields than PSSF in all cases (Table 3). This was likely due to the high glucose concentrations at the start of fermentation in

Table 3 Ethanol concentrations and ethanol yields during SSF and PSSF of steam-pretreated wheat straw

\begin{tabular}{|c|c|c|c|c|c|c|}
\hline $\mathrm{T}\left({ }^{\circ} \mathrm{C}\right)$ & WIS (\%) & $\begin{array}{l}\text { Fermentation } \\
\text { mode }\end{array}$ & $\begin{array}{l}\text { Duration of } \\
\text { experiment }(h)^{a}\end{array}$ & $\begin{array}{l}\text { Ethanol } \\
\text { conc }(g / L)\end{array}$ & $\begin{array}{l}\text { Ethanol yield (\%) } \\
\text { in the fermentation }\end{array}$ & $\begin{array}{l}\text { Ethanol } \mathrm{g} / 100 \mathrm{~g} \\
\text { dry straw }\end{array}$ \\
\hline 190 & 10 & SSF & 96 & 23.4 & 68 & 12.6 \\
\hline 200 & & & & 30.5 & 85 & 16.2 \\
\hline 210 & & & & 31.4 & 87 & 15.5 \\
\hline \multirow[t]{8}{*}{200} & 12.5 & SSF & 96 & 39.6 & 86 & 16.3 \\
\hline & & PSSF & $24+72$ & 34.0 & 74 & 14.0 \\
\hline & 15 & SSF & 96 & 48.3 & 85 & 16.1 \\
\hline & & PSSF & $24+72$ & 44.8 & 79 & 15.0 \\
\hline & 17.5 & SSF & 96 & 57.2 & 83 & 15.9 \\
\hline & & PSSF & $24+72$ & 52.9 & 78 & 14.7 \\
\hline & 20 & SSF & $192^{c}$ & 67.3 & 83 & 15.9 \\
\hline & & PSSF & $24+72$ & 59.0 & 74 & 13.9 \\
\hline
\end{tabular}

Ethanol yields are expressed as \% of theoretical and $\mathrm{g}$ ethanol produced per $100 \mathrm{~g}$ of dry straw. The maximum amount of ethanol that could be produced from $100 \mathrm{~g}$ dry straw is $18.5 \mathrm{~g}$

a Duration of prehydrolysis + duration of SSF

b $\%$ of theoretical, based on the glucan content in the pretreated solids

c Due to mixing difficulties, the SSF at $20 \%$ WIS was run for $192 \mathrm{~h}$ 
PSSF (results not shown), where the yeast utilized some of the glucose for cell growth, limiting the availability of glucose for ethanol formation and consequently lowering ethanol yields in comparison with the SSF configuration. A previous study compared SSF and PSSF on a small scale (total weight of 30-50 g) using pretreated wheat straw at 20 and $30 \%$ WIS content and the Cellic Ctec2 enzyme mixture [37]. Notably, the authors reported that the choice of configuration depended on the dry matter content, wherein SSF yielded more ethanol than PSSF at $20 \%$ WIS, consistent with our results, whereas PSSF was more favorable at $30 \%$ WIS. The authors attributed the better performance of SSF at $20 \%$ WIS to fast liquefaction and speculated that the worse performance of SSF at $30 \%$ WIS was due to the material remaining solid-like for much longer, decreasing the efficiency of the mixing.

Another study that used steam-pretreated sugarcane bagasse reported that PSSF configurations that implemented a 48-h prehydrolysis step prior to SSF had similar final ethanol yields and lower production costs than SSF setups [38]. To circumvent the difficulty of mixing at high WIS contents and achieve even distribution of enzymes and yeast, a short (1-3 h) fed-batch operation was introduced at the start of the experiment, and the solids concentration was increased gradually from $5 \%$ to the desired WIS content. In a similar investigation, a short $(6 \mathrm{~h})$ prehydrolysis step was combined with long $(36 \mathrm{~h})$ fed-batch SSF using unwashed steam-pretreated corn stover; a final ethanol concentration of $70.7 \mathrm{~g} / \mathrm{L}$, corresponding to an ethanol yield of $72.5 \%$, was obtained at a solids content of as high as $35.5 \%$ dry matter [36].

In our study, ethanol yields were calculated, assuming that the WIS content of the fermentation broth and the volume of the liquid fraction were constant throughout the SSF, although the total liquid volume changes during SSF-it increases with saccharification of insoluble polymers to soluble sugars and ethanol formation and decreases with water consumption in the hydrolysis of cellulose. According to Zhang and Bao [39], the increase in volume due to ethanol formation outpaces the decrease in volume due to water consumption, resulting in an overall gain in liquid volume during SSF. These authors proved that failing to consider the increase in total liquid volume leads to an underestimation of ethanol yields, and the underestimated error increases with greater ethanol concentrations. Having calculated the ethanol yields of SSF at solids loadings of 15, 20, 25, and $30 \%$ of steam-pretreated corn stover, the authors observed relative errors of underestimation of 4.6, 5.0, 5.7 , and $5.8 \%$, respectively, suggesting that the ethanol yields in our study should be approximately $4-5 \%$ higher. However, it remains possible to compare the results between experiments.
Furthermore, not only the ethanol yield, but also the final ethanol concentration is important in the fermentation step. According to Galbe et al. [40], to significantly decrease the energy demand in the distillation step, at least $40-50 \mathrm{~g} / \mathrm{L}$ ethanol must be attained in the fermentation broth. In our study, the ethanol concentrations were at least $40 \mathrm{~g} / \mathrm{L}$ by SSF at WIS contents of $12.5 \%$ and above, peaking $(67.3 \mathrm{~g} / \mathrm{L})$ after $192 \mathrm{~h}$ of SSF at $20 \%$ WIS (Table 3); however, this residence time is likely not realistic from an economic point of view.

\section{Anaerobic digestion}

The methane potential of the hydrolysate (the liquid fraction of steam pretreated material) and the filtered thin stillage (residues after distillation of ethanol) from the SSF experiments was examined in 7-day anaerobic digestion (AD). The ethanol concentration in the thin stillage was measured before $\mathrm{AD}$ to ensure that most of the ethanol was removed during distillation. In an industrial process, the solid fraction after pretreatment would likely be washed and filtered, and the washing liquid would be combined with the hydrolysate before being passed on to the AD. To better mimic these conditions, the hydrolysate was diluted 1.5 times with water before AD. Table 4 presents the methane potentials and methane yields of the samples. All results were corrected with a blank that contained only inoculum and were run in parallel with the other samples.

The methane potential of the hydrolysate was $321 \mathrm{NL} /$ $\mathrm{kg}$ VS, whereas that of SSF stillage rose from 376 to $439 \mathrm{NL} / \mathrm{kg}$ VS with increasing WIS. This was possibly due to the lack of xylose fermentation, which resulted in higher xylose concentration of the stillage at increasing WIS content in SSF.

A typical $\mathrm{AD}$ test is very time-consuming and usually proceeds for at least 30 days. In our study, the duration of the AD experiments was 7 days (168 h), which likely

\begin{tabular}{|c|c|c|c|}
\hline $\begin{array}{l}\text { WIS (\%) } \\
\text { in SSF }\end{array}$ & Substrate in $A D$ & $\begin{array}{l}\text { Methane } \\
\text { potential (NL/kg } \\
\text { VS) }\end{array}$ & $\begin{array}{l}\text { Methane } \mathrm{g} / 100 \mathrm{~g} \\
\text { dry straw }\end{array}$ \\
\hline & Hydrolysate & 321 & 4.8 \\
\hline 10 & Thin stillage & 376 & 1.2 \\
\hline 12.5 & Thin stillage & 392 & 1.0 \\
\hline 15 & Thin stillage & 410 & 1.1 \\
\hline 17.5 & Thin stillage & 424 & 1.0 \\
\hline 20 & Thin stillage & 439 & 1.0 \\
\hline
\end{tabular}

Methane potentials are expressed as volume of methane produced in normal liter per $\mathrm{kg}$ volatile solids, NL/kg VS. Methane yields are expressed as g methane produced per $100 \mathrm{~g}$ dry wheat straw 
does not reflect the total methane potential of the samples. However, our aim was to test the degradability of the hydrolysate and thin stillage-not to maximize methane production.

Despite the short experiments, the methane potentials of steam-pretreated wheat straw-derived samples were in the same range as in other studies. Kaparaju et al. [11] reported methane potentials of $384 \mathrm{NL} / \mathrm{kg}$ VS for a hydrolysate that was obtained after hydrothermal pretreatment of wheat straw, $324 \mathrm{NL} / \mathrm{kg}$ VS for wheat straw stillage from a lab-scale experiment, and $485 \mathrm{NL} /$ $\mathrm{kg}$ VS for stillage from a Swedish industrial plant that produces ethanol from wheat straw and grain. Another study measured the methane potential of molasses from the liquid fraction after hydrothermal pretreatment and part of the thin stillage in Inbicon's demonstration plant by 2 independent AD tests, generating values of 355 and $384 \mathrm{NL} / \mathrm{kg}$ VS [13].

We also calculated methane yields expressed as g methane per $100 \mathrm{~g}$ dry straw to compare them with ethanol yields. The methane yield using hydrolysate was 4.8 versus $1 \mathrm{~g}$ methane per $100 \mathrm{~g}$ dry straw with the thin stillage (Table 4). This result is expected, because although the methane potentials of the hydrolysate and the stillage are in the same range, the total amount of organic matter that can be digested easily to methane is significantly greater in the hydrolysate that is obtained after steam pretreatment of $100 \mathrm{~g}$ dry straw than in the stillage that remains after SSF of the solids from the same pretreatment.

\section{Overall product yields}

The SSF and AD results were evaluated by comparing the total mass yields of ethanol, methane, and combustible lignin-rich solid residue (residue after SSF without ash) in g/100 g dry straw. As shown in Fig. 1, the total amounts of products were similar at all WIS contents-between 44 and 47/100 g dry straw. These results were lower than those on acetic acid-pretreated corn stover, in which the total amount of products was slightly higher than $50 / 100$ g dry corn stover [19]. This difference was due in part to higher methane yields with corn stover-derived samples. As discussed, we might have underestimated the methane and ethanol yields in the present study.

\section{Modeling}

\section{Energy and mass balances}

The mass and energy flows for the 9 configurations are listed in Table 5. The energy flows were based on the LHVs that were calculated from the heat of combustion values of the materials. The configurations are denoted C10-96, C12.5-96, C15-96, C17.5-96, C20-96, C20$120, \mathrm{C} 20-144, \mathrm{C} 20-168$, and $\mathrm{C} 20-192$, in which the first number refers to the WIS content in the simulations

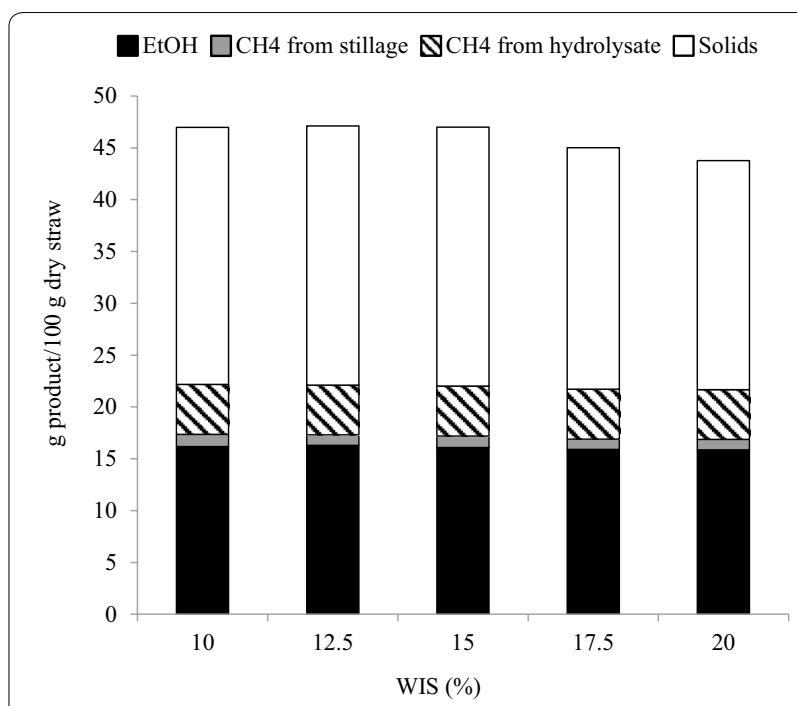

Fig. 1 Total mass yield in g product/100 g dry wheat straw. Ethanol was produced from the solid fraction of pretreated wheat straw in SSF at $10-20 \%$ WIS. Methane was produced in AD from the liquid fraction (hydrolysate) of pretreated wheat straw and from the thin stillage. The solid residue was obtained after filtration of the SSF broth

(10-20\% WIS) and the second number is the residence time in the fermentation for the economic evaluations (96-192 h). The mass and energy flow results for the $20 \%$ WIS configuration were based on the ethanol yield at a residence time of $192 \mathrm{~h}$ by SSF in the experimental trials. The residence time in the SSF was then varied in the economic assessments for the $20 \%$ WIS setup to determine the impact on NPV when the residence time was lowered.

As seen in Table 5, between 4.6 and 4.8 tonnes/h of ethanol were generated from 25 tonnes of dry straw/h, corresponding to an annual ethanol production of approximately $37,000 \mathrm{~m}^{3}$. Because the residence time was altered for the $20 \%$ WIS configuration only in the economic evaluations, all configurations with $20 \%$ WIS had the same material and heat flows, but the electricity demand differed slightly. Table 5 also shows that electricity had to be purchased in all cases; thus, no electricity was sold to the grid. The amount of biogas that was produced in the anaerobic digestion step varied between 3.3 and 3.4 tonnes $/ \mathrm{h}$. Approximately $0.28 \mathrm{~kg}$ methane $/ \mathrm{kg} \mathrm{VS}$ and $0.15 \mathrm{~kg}$ methane $/ \mathrm{kg}$ COD in the incoming stream to the anaerobic digestion in the simulations was produced in all configurations. The amount of solid fuels that could be produced increased from 4.1 to $5.1 \mathrm{~kg} / \mathrm{h}$ with increasing WIS content.

The energy efficiency for the products (in terms of the energy content in the products divided by the incoming energy added to the process; see Eq. 1) is shown in Fig. 2. The heat and electricity demand to produce $1 \mathrm{~kg}$ of ethanol in the various configurations is shown in Fig. 3. 
Table 5 The mass and energy flows for the nine configurations

\begin{tabular}{|c|c|c|c|c|c|c|c|c|c|}
\hline & C10-96 & C12.5-96 & C15-96 & C17.5-96 & C20-96 & C20-120 & C20-144 & C20-168 & C20-192 \\
\hline \multicolumn{10}{|l|}{ Input } \\
\hline \multicolumn{10}{|c|}{ Raw material } \\
\hline Tonne/h & 25 & 25 & 25 & 25 & 25 & 25 & 25 & 25 & 25 \\
\hline MW & 136 & 136 & 136 & 136 & 136 & 136 & 136 & 136 & 136 \\
\hline \multicolumn{10}{|l|}{ Molasses } \\
\hline Tonne/h & 1.4 & 1.1 & 0.9 & 0.7 & 0.7 & 0.7 & 0.7 & 0.7 & 0.7 \\
\hline MW & 2.8 & 2.2 & 1.7 & 1.4 & 1.3 & 1.3 & 1.3 & 1.3 & 1.3 \\
\hline \multicolumn{10}{|l|}{ Enzymes } \\
\hline Tonne/h & 0.1 & 0.1 & 0.1 & 0.1 & 0.1 & 0.1 & 0.1 & 0.1 & 0.1 \\
\hline MW & 0.4 & 0.4 & 0.4 & 0.4 & 0.4 & 0.4 & 0.4 & 0.4 & 0.4 \\
\hline \multicolumn{10}{|c|}{ Electricity external } \\
\hline MW & 0.5 & 0.7 & 0.6 & 0.5 & 0.9 & 1.0 & 1.0 & 1.1 & 1.2 \\
\hline \multicolumn{10}{|c|}{ Harvesting and transportation } \\
\hline MW & 4.4 & 4.4 & 4.4 & 4.4 & 4.4 & 4.4 & 4.4 & 4.4 & 4.4 \\
\hline \multicolumn{10}{|l|}{ Water } \\
\hline Tonne/h & 221 & 203 & 195 & 194 & 184 & 184 & 184 & 184 & 184 \\
\hline MW & 0.0 & 0.0 & 0.0 & 0.0 & 0.0 & 0.0 & 0.0 & 0.0 & 0.0 \\
\hline \multicolumn{10}{|l|}{ Products } \\
\hline \multicolumn{10}{|l|}{ Ethanol } \\
\hline Tonne/h & 4.7 & 4.7 & 4.7 & 4.6 & 4.8 & 4.8 & 4.8 & 4.8 & 4.8 \\
\hline MW & 28 & 28 & 27 & 27 & 28 & 28 & 28 & 28 & 28 \\
\hline \multicolumn{10}{|l|}{ Methane } \\
\hline Tonne/h & 3.4 & 3.4 & 3.4 & 3.4 & 3.3 & 3.3 & 3.3 & 3.3 & 3.3 \\
\hline MW & 47 & 47 & 47 & 47 & 46 & 46 & 46 & 46 & 46 \\
\hline \multicolumn{10}{|c|}{ Solid fuel (pellet dry) } \\
\hline Tonne/h & 4.1 & 4.5 & 4.8 & 4.9 & 5.1 & 5.1 & 5.1 & 5.1 & 5.1 \\
\hline MW & 24 & 26 & 28 & 28 & 30 & 30 & 30 & 30 & 30 \\
\hline \multicolumn{10}{|c|}{ Electricity produced } \\
\hline MW & 3.3 & 2.8 & 2.6 & 2.6 & 2.2 & 2.2 & 2.2 & 2.2 & 2.2 \\
\hline \multicolumn{10}{|c|}{ Carbon dioxide } \\
\hline Tonne/h & 4.1 & 4.1 & 3.9 & 3.8 & 3.9 & 3.9 & 3.9 & 3.9 & 3.9 \\
\hline MW & 0.0 & 0.0 & 0.0 & 0.0 & 0.0 & 0.0 & 0.0 & 0.0 & 0.0 \\
\hline
\end{tabular}

Figure 2 shows the ratio of energy in the outgoing products to the incoming energy for the process. The overall energy efficiency varied from 68 to $72 \%$; the configuration with the lowest WIS content in the SSF (C10-96) effected the lowest efficiency.

As seen in Fig. 3, the total heat and electricity requirements for the process per $\mathrm{kg}$ ethanol produced varied between 15 and $19 \mathrm{MJ} / \mathrm{kg}$ ethanol. Electricity was calculated, based on the electrical energy that was generated in the turbines and the actual requirements of the process from the Aspen Process Economic Analyzer (APEA) and the vendor's quotation. The highest heat and electricity demand was attained for C10-96, due to the high water content in the SSF at $10 \%$ WIS, leading to low final ethanol concentrations in the fermentation broth, and the large amount of water that was to be processed downstream. Higher water content and longer residence time also increased the electricity demand in the fermentation stage, resulting in greater electricity requirements. In the

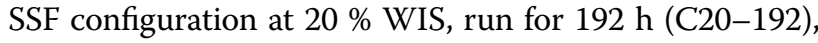
the electricity demand was higher versus the setup for $96 \mathrm{~h}$ (C20-96).

\section{Economics}

To evaluate the profitability of the plants that were assumed to be located in Sweden, we calculated the NPV for the 9 configurations, based on an investment lifetime of 20 years and a discount rate of $11 \%$. The overall NPV, MESP, capital cost, and cash flow NPV for these configurations are presented in Fig. 4. 


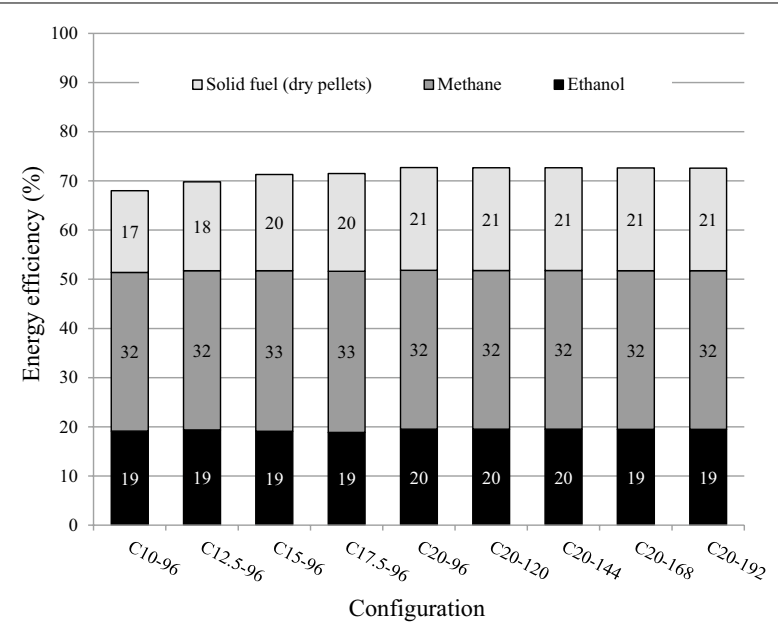

Fig. 2 Energy efficiency of products. Energy efficiency is expressed as the energy content in the products divided by the incoming energy. The energy content was based on the LHV calculated from the heat of combustion values for the various materials. The incoming energy consists of the energy in the raw material, enzymes, and molasses and the energy for harvest and transport of the raw materials. The configurations are denoted C10-96, C12.5-96, C15-96, C17.5-96, C20-96, C20-120, C20-144, C20-168, and C20-192, where the first number refers to the WIS content in SSF (in \%) followed by the time that was set for the SSF (in hour)

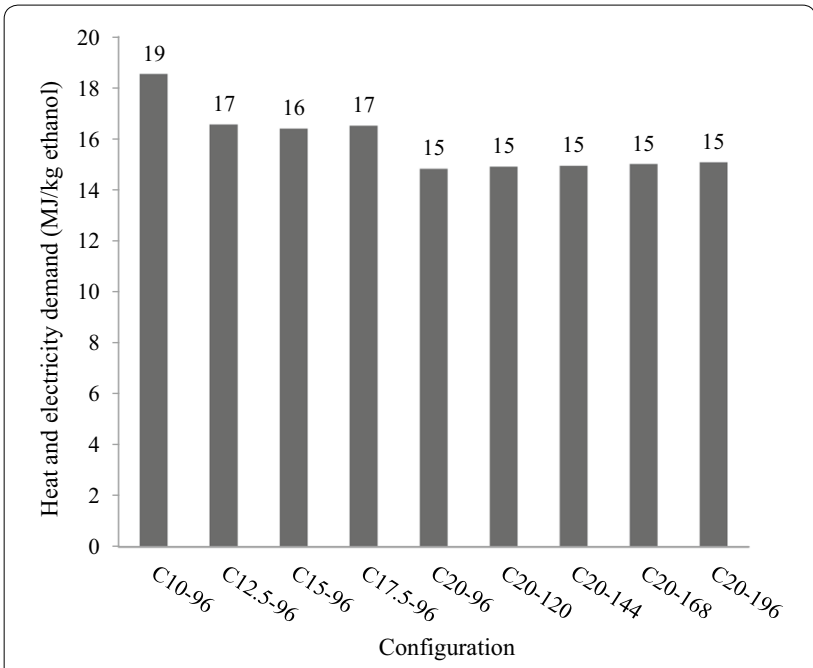

Fig. 3 Heat and electricity requirements to produce $1 \mathrm{~kg}$ of ethanol and associated coproducts. The configurations are denoted C10-96, C12.5-96, C15-96, C17.5-96, C20-96, C20-120, C20-144, C20-168, and C20-192, where the first number refers to the WIS content in SSF (in \%) followed by the time that was set for the SSF (in hour)

All cases had negative NPVs at an $11 \%$ discount rate under the conditions in the "Cost calculations" in "Methods" section. As expected, the NPV increased with increasing WIS concentration, and declined with higher residence times, peaking for C20-96 ( -0.4 MEUR). Further, increasing the residence time to $192 \mathrm{~h}(\mathrm{C} 20-192)$ influenced the NPV negatively to a smaller extent than lowering the WIS to $12.5 \%$ (C12.5-96). Similarly, capital costs were higher with decreasing WIS content and greater residence time due to the need for larger fermentation vessels. Configuration C10-96 had the lowest cash flow, because the most diluted process stream requires the most energy, decreasing the production of pellets that were available for sale.

MESP values ranged from $0.72(\mathrm{C} 20-96)$ to 0.87 (C10-96) EUR/L ethanol. Kravanja et al. [35] reported ethanol production costs from straw of approximately 0.48-0.63 EUR/L ethanol for various biorefinery configurations at a $5 \%$ discount rate and 15 years of depreciation. In our study, the MESP at a $5 \%$ discount rate and a 20-year lifetime was $0.57-0.68$ EUR/L ethanol. Also, even with high energy efficiency, plants can have a negative NPV. The NPV depends in part on the cost of the raw material and the income from the products and is not always reflected by the total energy content of the products alone.

The cash flow NPV was broken down into various operational costs and revenues, which are shown with the capital costs in Fig. 5.

Figure 5 shows that the raw material represented the largest operational cost and that the revenue from the ethanol was the largest source of income. Also, income was earned from the electricity, despite none being sold to the grid, because the income from green electricity certificates was included in the profit calculations.

\section{Sensitivity analysis and process modification Sensitivity analysis}

To determine the influence of the discount rate on the profitability of the plant, the internal rate of return (IRR) and the NPV at a $5 \%$ discount rate were calculated for all configurations. IRRs and NPVs at discount rates of 5 and $11 \%$ are presented in Table 6 . An imposed taxation of 20 and $30 \%$ was also examined for the configurations at a $5 \%$ discount rate. These calculations were not possible for the setups at the $11 \%$ discount rate due to their negative NPVs. The results for the various taxation rates are listed in Table 6.

As seen in Table 6, the IRRs and NPVs at the $5 \%$ discount rate were highest for C20-96 (10.95\% and 73 MEUR, respectively) and lowest for C10-96 (6.6\% and 22 MEUR, respectively). The IRRs for all configurations were greater than $5 \%$, which can be comparable with a risk free-asset return on an investment. A lower discount rate can thus render a configuration profitable. At a $5 \%$ discount rate and with a 10-year depreciation, the NPV was positive in all configurations for both taxation rates. 


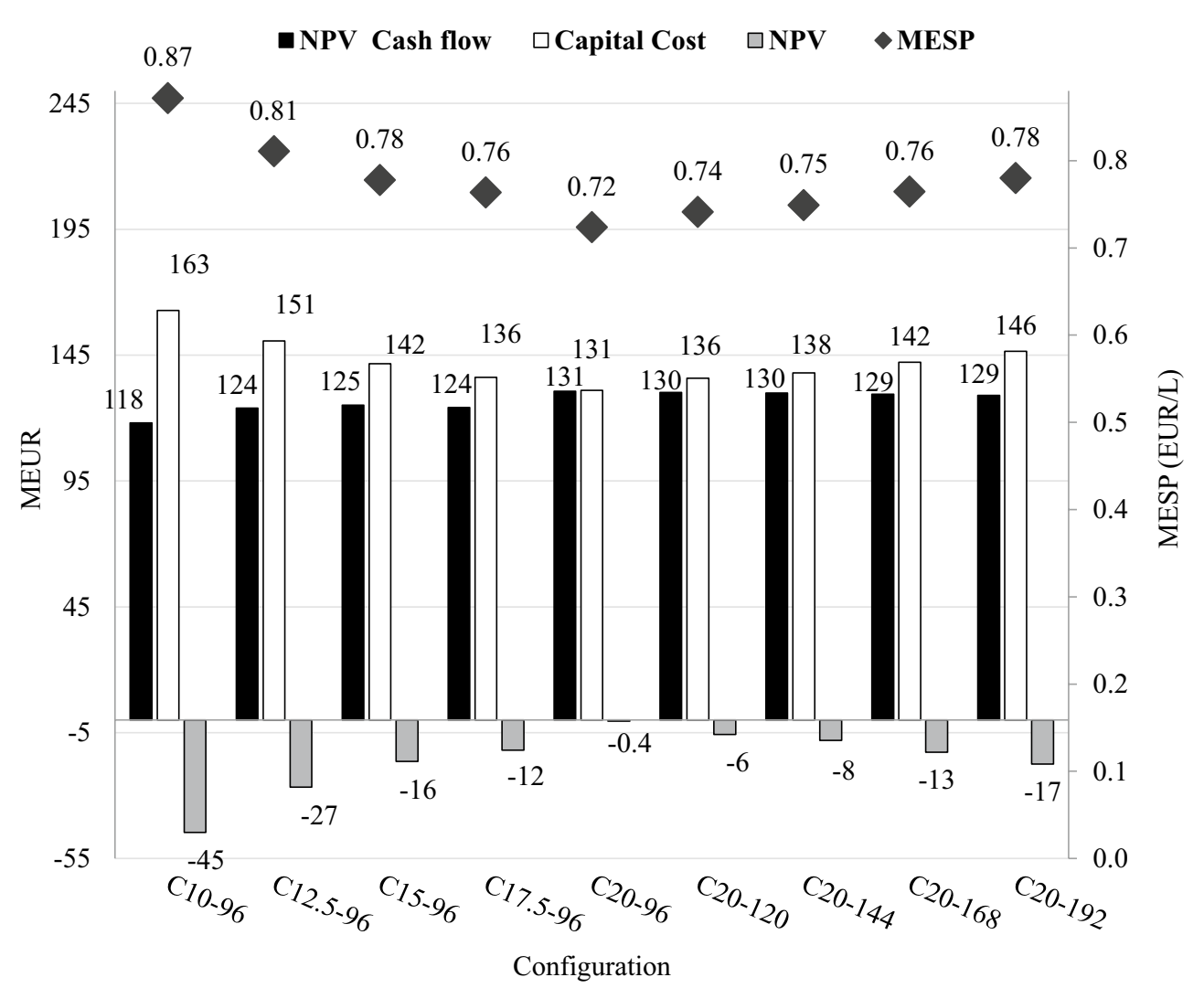

Fig. 4 Capital cost, MESP, overall NPV, and cash flow NPV at an $11 \%$ discount rate. The configurations are denoted C10-96, C12.5-96, C15-96, C17.5-96, C20-96, C20-120, C20-144, C20-168, and C20-192, where the first number refers to the WIS content in SSF (in \%) followed by the time that was set for the SSF (in hour)

The price of biogas was increased from the base case price of $33 \mathrm{EUR} / \mathrm{MWh}$ (corresponding to $100 \%$ ) to 67 EUR/MWh (corresponding to $200 \%$ ) to determine its effects on the NPV (Fig. 6). When the price of the biogas increased by $20 \%$, all configurations except for C10-96 and C12.5-96 had a positive NPV. Thus, an increase in raw biogas prices might make an ethanol plant more profitable.

\section{Process modifications}

To determine whether the profitability of the configurations could be improved, 2 additional evaluations were conducted. First the NPV was calculated for the various configurations assuming that the raw biogas was upgraded to vehicle fuel quality. Secondly, the C17.5-96 configuration was altered to include fermentation of xylose. The hydrolysis stream after pretreatment was then added to the SSF in the simulation and the xylose was cofermented with glucose to ethanol instead of being fed to the anaerobic digestion. For the configuration with xylose fermentation (denoted C17.5-96X), an upgrade in biogas to vehicle fuel quality was not considered. Our assumptions for the biogas upgrade to vehicle fuel quality and the changes in the configuration due to xylose fermentation are detailed in "Sensitivity and process modification" in "Methods" section.

The NPVs for the biogas upgrade and xylose fermentation at an $11 \%$ discount rate are shown in Fig. 7.

All configurations attained a positive NPV at an $11 \%$ discount rate when the biogas was upgraded to vehicle fuel quality or the xylose was converted to ethanol. The MESP varied from 0.46 to $0.60 \mathrm{EUR} / \mathrm{L}$ ethanol, corresponding to a decrease of approximately $0.27 \mathrm{EUR} / \mathrm{L}$ ethanol compared with no upgrade of the biogas to vehicle fuel quality. C17.5-96X had a higher NPV and MESP than the C17.5-96 configuration, the latter of which was due to the lower synthesis of co-products.

These results suggest that the fermentation of hexoses alone during ethanol production from wheat straw is insufficient to render the plants profitable at the WIS concentrations and ethanol yields in our study, given the assumptions in the economic evaluation. However, fermentation of xylose to ethanol or upgrade of the biogas to vehicle fuel standard might improve their profitability. 


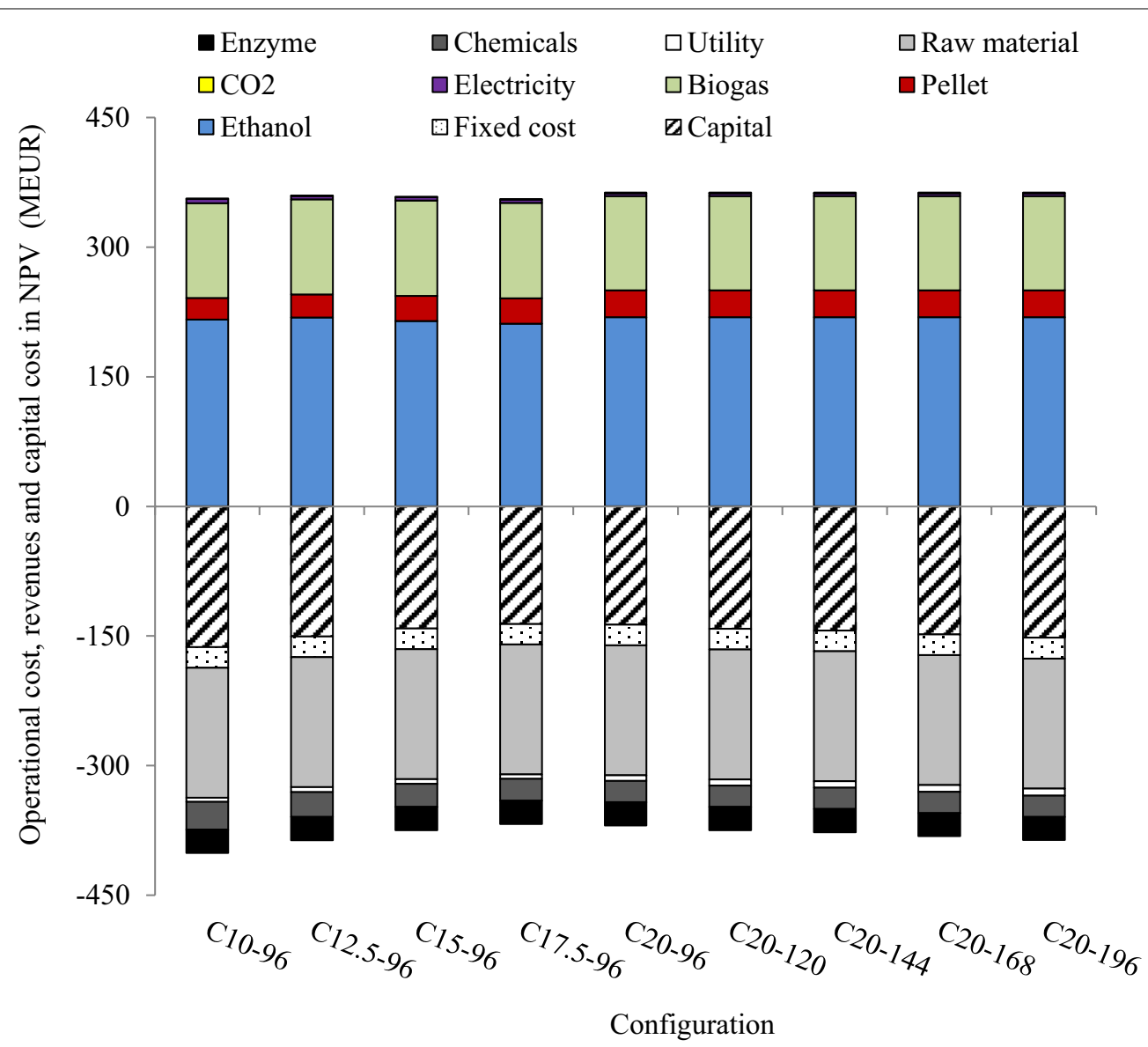

Fig. 5 NPV of capital costs, operational costs, and revenues. The configurations are denoted C10-96, C12.5-96, C15-96, C17.5-96, C20-96, C20-120, C20-144, C20-168, and C20-192, where the first number refers to the WIS content in SSF (in \%) followed by the time that was set for the SSF (in hour)

Table 6 IRRs and NPVs

\begin{tabular}{|c|c|c|c|c|c|}
\hline Configuration & IRR (\%) & $\begin{array}{l}\text { NPV at } 5 \% \\
\text { discount } \\
\text { rate (MEUR) }\end{array}$ & $\begin{array}{l}\text { NPV at } 11 \% \\
\text { discount } \\
\text { rate (MEUR) }\end{array}$ & $\begin{array}{l}\text { NPV with } 20 \% \text { taxation } \\
\text { at } 5 \% \text { discount } \\
\text { rate (MEUR) }\end{array}$ & $\begin{array}{l}\text { NPV with } 30 \% \text { taxation } \\
\text { at } 5 \% \text { discount } \\
\text { rate (MEUR) }\end{array}$ \\
\hline C10-96 & 6.6 & 22 & -45 & 10 & 4 \\
\hline C12.5-96 & 8.2 & 43 & -27 & 28 & 20 \\
\hline C15-96 & 9.2 & 54 & -16 & 37 & 28 \\
\hline C17.5-96 & 9.6 & 58 & -12 & 40 & 31 \\
\hline C20-96 & 11.0 & 73 & -0.4 & 53 & 42 \\
\hline C20-120 & 10.4 & 68 & -6 & 48 & 38 \\
\hline C20-144 & 10.1 & 65 & -8 & 46 & 36 \\
\hline C20-168 & 9.6 & 60 & -13 & 42 & 33 \\
\hline C20-192 & 9.1 & 55 & -17 & 38 & 29 \\
\hline
\end{tabular}

IRRs and NPVs at 5 and $11 \%$ discount rate, and NPVs at 20 and $30 \%$ corporate taxation and $5 \%$ discount rate

The alternative that is the most profitable will depend on the price that is assigned to the ethanol and biogas and the amount of ethanol that can be produced from the xylose. At a biogas price for upgraded biogas to vehicle fuel quality of approximately 67 EUR/MWh and a price of ethanol of $123 \mathrm{EUR} / \mathrm{MWh}$ (corresponding to $0.67 \mathrm{EUR} / \mathrm{L}$ ), the profitability of xylose fermentation is higher than by upgrading the biogas to vehicle 


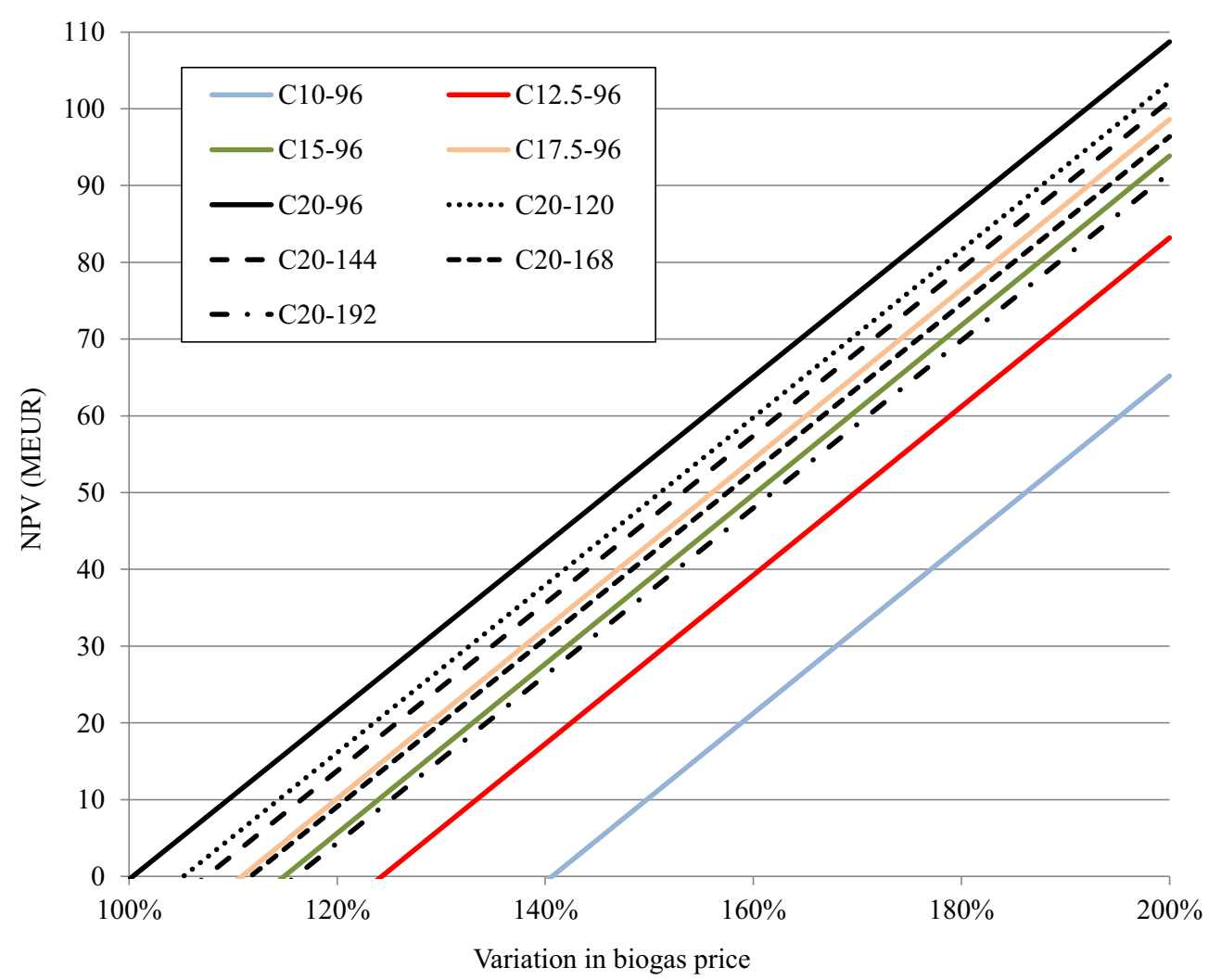

Fig. 6 Effects of variations in the price of biogas on NPV. The configurations are denoted C10-96, C12.5-96, C15-96, C17.5-96, C20-96, C20-120, C20-144, C20-168, and C20-192, where the first number refers to the WIS content in SSF (in \%) followed by the time that was set for the SSF (in hour)

fuel quality. However, the potential xylose conversion to ethanol at high WIS concentrations must be evaluated in additional studies.

\section{Conclusions}

In the experimental part of our study, acetic acid was found to be a suitable impregnation agent in the steam pretreatment of wheat straw. The removal of the liquid fraction, which contained inhibitory compounds, such as organic acids and furfural, after pretreatment made it possible to perform SSF at high solids contents and thus achieve high ethanol concentrations. The maximum ethanol concentration $(67.3 \mathrm{~g} / \mathrm{L})$ was obtained when SSF was run at $20 \%$ WIS.

SSF was robust at between 10 and $20 \%$ WIS loadingssimilar ethanol yields (above $80 \%$ ) in the SSF step were obtained in all cases, independent of WIS concentration. However, to achieve the same yield at $20 \%$ as at $10 \%$ WIS, the residence time had to be doubled.

Ethanol yields were higher by SSF than PSSF at all WIS contents. Yet, we believe that at WIS contents above $20 \%$, including a prehydrolysis step at $45-50{ }^{\circ} \mathrm{C}$ before SSF or running SSF in fed-batch mode will be necessary to lower the residence time, effect sufficient mixing, and avoid inhibition of enzymes and yeast. The methane potential of wheat straw hydrolysate and thin stillage was in the same range as reported in earlier studies $[11,13]$.

Based on our techno-economic assessments, a high energy efficiency of transforming raw material into product does not necessarily equate to a profitable plant, due to the large variations in the cost of raw materials and the prices of the products. Moreover, using wheat straw as raw material under our economic assumptions (including an $11 \%$ discount rate), the fermentation of hexoses to ethanol and the raw biogas production from xylose did not result in a positive NPV at WIS loadings of up to $20 \%$ in the SSF. However, at a $5 \%$ discount rate, all configurations attained a positive NPV. Upgrading the biogas to vehicle fuel quality and fermenting xylose to ethanol proved to have a good potential to improve the profitability of the plants. Fermentation of xylose effected a higher NPV than upgrading the biogas to vehicle fuel quality at the corresponding WIS concentration. However, to identify the most profitable solutions, further studies must be performed. 


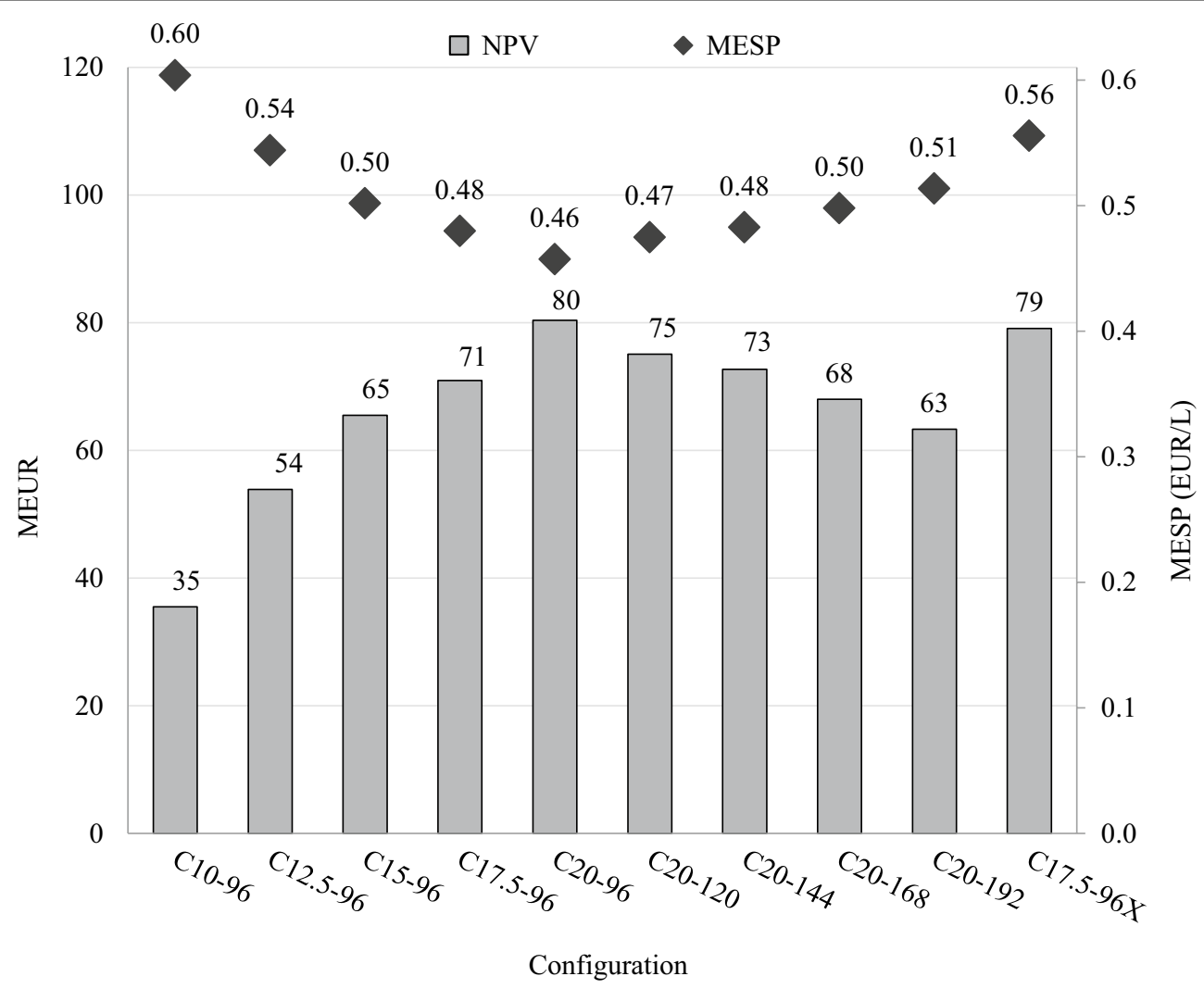

Fig. 7 NPVs and MESPs of the configurations on biogas upgrade and xylose fermentation. The configurations are denoted C10-96, C12.5-96, C15-96, C17.5-96, C20-96, C20-120, C20-144, C20-168, and C20-192, where the first number refers to the WIS content in SSF (in \%) followed by the time that was set for the SSF (in hour). In configuration C17.5-96X, xylose fermentation was considered

\section{Methods}

\section{Experimental part}

\section{Raw material}

Wheat straw at $89 \%$ DM was provided by the State Grid Corporation of China. The raw material was milled and sieved to obtain 2 to $10-\mathrm{mm}$ pieces and then stored at $4{ }^{\circ} \mathrm{C}$ before pretreatment. The composition of wheat straw was analyzed for structural carbohydrates, lignin, ash, and extractives according to the National Renewable Energy Laboratory (NREL) procedure [41]. The wheat straw contained (\% of DM) $32.7 \%$ glucan, $23.4 \%$ xylan, $4.7 \%$ arabinan, $1.8 \%$ ash, $16.7 \%$ acid insoluble lignin, $5.5 \%$ acid soluble lignin, and $13.4 \%$ extractives.

\section{Steam pretreatment}

The raw material was soaked in an aqueous solution that contained $1 \mathrm{wt} \%$ acetic acid in sealed buckets at room temperature for $60 \mathrm{~min}$. The total weight of liquid was 20 times that of the dry wheat straw. The soaked materials were dewatered in a 5-L automatic filter press (Tinkturenpressen HP5 M, Fischer Maschinenfabrik GmbH, Germany) to a DM content of $45-52 \%$.
Wheat straw was steam-pretreated in a 10-L unit as described [19], in which $400 \mathrm{~g}$ dry weight straw was loaded into the reactor at a time. The temperature during the pretreatment ranged from 190 to $210^{\circ} \mathrm{C}$, and the residence time was $10 \mathrm{~min}$.

The solid fraction after pretreatment was analyzed for structural carbohydrates, lignin, and ash, and the liquid fraction was examined with regard to oligomeric and monomeric sugars, organic acids, and sugar degradation products according to NREL protocols $[41,42]$.

\section{Yeast cultivation}

Inoculum culture Baker's yeast (S. cerevisiae), produced by Jästbolaget $\mathrm{AB}$ (Rotebro, Sweden), was incubated on an agar plate at $30^{\circ} \mathrm{C}$ for $24 \mathrm{~h}$. The cells were then added to a $300-\mathrm{mL}$ cotton-plugged Erlenmeyer flask that contained $70 \mathrm{~mL}$ sterile medium at $\mathrm{pH} 5$, comprising $23.8 \mathrm{~g} / \mathrm{L}$ glucose, $10.8 \mathrm{~g} / \mathrm{L}$ $\left(\mathrm{NH}_{4}\right)_{2} \mathrm{SO}_{4}, 5.0 \mathrm{~g} / \mathrm{L} \mathrm{H}_{2} \mathrm{KPO}_{4}, 1.1 \mathrm{~g} / \mathrm{L} \mathrm{MgSO}_{4} 7 \mathrm{H}_{2} \mathrm{O}, 14 \mathrm{~mL} / \mathrm{L}$ trace metal solution, and $1.4 \mathrm{~mL} / \mathrm{L}$ vitamin solution. The compositions of the trace metal and vitamin solutions have been described by Taherzadeh et al. [43]. The flask was incubated on a rotary shaker at $180 \mathrm{rpm}$ and $30^{\circ} \mathrm{C}$ for $24 \mathrm{~h}$. 
Aerobic batch cultivation on glucose Sixty milliliters of inoculum was added to a 2-L fermentor (Infors AG, Bottmingen, Switzerland) that contained $500 \mathrm{~mL}$ of sterile medium. The medium comprised $20 \mathrm{~g} / \mathrm{L}$ glucose, $\left.22.5 \mathrm{~g} / \mathrm{L}_{(} \mathrm{NH}_{4}\right)_{2} \mathrm{SO}_{4}$, $10.5 \mathrm{~g} / \mathrm{L} \mathrm{H}_{2} \mathrm{KPO}_{4}, 2.2 \mathrm{~g} / \mathrm{L} \mathrm{MgSO}_{4} 7 \mathrm{H}_{2} \mathrm{O}, 60 \mathrm{~mL} / \mathrm{L}$ trace metal solution, and $6 \mathrm{~mL} / \mathrm{L}$ vitamin solution. The $\mathrm{pH}$ was adjusted to 5 with $10 \mathrm{wt} \% \mathrm{NaOH}$ and maintained by automatic control. The batch cultivation was performed at $30^{\circ} \mathrm{C}$ at $700 \mathrm{rpm}$ and an aeration rate of $0.5 \mathrm{~L} / \mathrm{min}$.

Aerobic fed-batch cultivation on hydrolysate Feeding of the hydrolysate began when the concentration of dissolved oxygen increased rapidly, indicating that the carbon source had been depleted. A total volume of $1 \mathrm{~L}$ of feed that contained sterilized hydrolysate ( $\mathrm{pH}$ adjusted to 5 with 10 wt $\% \mathrm{NaOH}$ ), supplemented with glucose and salt solution, yielding a feed concentration of $26 \mathrm{~g} / \mathrm{L}$ glucose, $11.3 \mathrm{~g} / \mathrm{L}\left(\mathrm{NH}_{4}\right)_{2} \mathrm{SO}_{4}, 5.3 \mathrm{~g} / \mathrm{L} \mathrm{KH}_{2} \mathrm{PO}_{4}$, and $1.1 \mathrm{~g} / \mathrm{L}$ $\mathrm{MgSO}_{4} 7 \mathrm{H}_{2} \mathrm{O}$, was added over 22-24 h. Fed-batch cultivation was performed at $800 \mathrm{rpm}$ and an aeration rate of $1.5 \mathrm{vvm}$. Yeast cells were harvested by centrifugation in $750-\mathrm{mL}$ containers at $3500 \mathrm{rpm}$ for 5-10 min.

\section{Combining ethanol and biogas production}

The configuration for the combined production of ethanol and biogas is shown in Fig. 8. After steam pretreatment, the solid fraction (C6 stream) was washed in a dewatering step in a 3-L press (Tinkturenpressen HP5 M, Fischer Maschinenfabrik GmbH, Germany), followed by the addition of the same amount of water that had been expelled. Then, the material was pressed to a DM content of $45-52 \%$ and diluted with water to obtain the desired water-insoluble solids (WIS) content (10-20\%) in the SSF. The hydrolysate that was obtained after pretreatment (C5

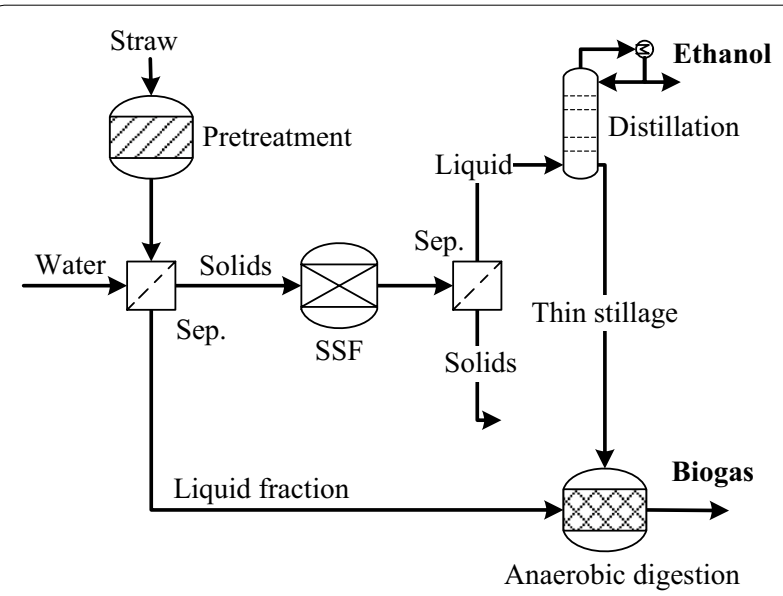

Fig. 8 Configuration used in the experiments for the combined production of ethanol and biogas from wheat straw stream) and the liquid fraction after filtration of the distillation residue (thin stillage) were used in the $\mathrm{AD}$ to produce biogas. The solids from the SSF residue, which were primarily lignin, were not evaluated further in our study.

\section{Simultaneous saccharification and fermentation}

SSF was performed using the solid fractions of pretreated materials in 2-L fermentors (Infors AG Bottmingen, Switzerland). The materials were sterilized in the fermentors using an autoclave. The nutrients, sterilized separately, were added to the fermentors at $0.5 \mathrm{~g} / \mathrm{L}\left(\mathrm{NH}_{4}\right)_{2} \mathrm{HPO}_{4}$, $0.025 \mathrm{~g} / \mathrm{L} \mathrm{MgSO}_{4} 7 \mathrm{H}_{2} \mathrm{O}$, and $1.0 \mathrm{~g} / \mathrm{L}$ yeast extract. The enzyme preparation, Cellic Ctec2 from Novozymes A/S (Bagsvaerd, Denmark), was used at 10 filter paper units (FPU)/g WIS. The yeast that was cultivated on the hydrolysate was added to the fermentors at $3 \mathrm{~g}$ dry yeast/L. The total weight of the SSF was $1000 \mathrm{~g}$, the temperature was set to $35{ }^{\circ} \mathrm{C}$, and the $\mathrm{pH}$ was maintained automatically at 5.0 with $10 \mathrm{wt} \% \mathrm{NaOH}$. Agitation was provided with a stirrer, equipped with a pitched-blade impeller and an anchor mixer, at $700 \mathrm{rpm}$. The SSF experiments were carried out for $96-192 \mathrm{~h}$.

At $12.5-20 \%$ WIS, SSF with 24-h prehydrolysis (PSSF) was also examined. In PSSF, the solids were partially hydrolyzed by the enzymes at $45^{\circ} \mathrm{C}$ for $24 \mathrm{~h}$; then, the medium was cooled to $35^{\circ} \mathrm{C}$, and the yeast was added.

Samples were withdrawn regularly during SSF and PSSF and analyzed for ethanol, sugars, acetic acid, lactic acid, glycerol, formic acid, HMF, and furfural content.

\section{Anaerobic digestion}

The material from the SSF was filtered, and ethanol from the filtrate was distilled in a lab-scale distillation unit. The residue, which is termed thin stillage, and the hydrolysate from the pretreatment step were used as substrates in the anaerobic digestion (AD) to determine their methane potential.

Active sludge from an anaerobic digester at Domsjö Industries (Domsjö, Sweden) was used as the inoculum. The volatile solids (VS) content in the inoculum and substrate was measured, and the ratio of inoculum to substrate was 3:2 (w:w), based on VS content.

$\mathrm{AD}$ was performed in 1-L reactors at a total working weight of $500 \mathrm{~g}$. Before startup, the headspace of the reactors was flushed with nitrogen for $1 \mathrm{~min}$ to ensure that an anaerobic environment was generated. The reactors were incubated at $37^{\circ} \mathrm{C}$ in a water bath and mixed continuously with magnetic stirrers for $168 \mathrm{~h}$. Due to the $\mathrm{pH}$-sensitivity of methanogenic microorganisms, the $\mathrm{pH}$ of the substrates was set to 7 with $10 \mathrm{wt} \% \mathrm{NaOH}$ solution. To determine the background biogas production from the inoculum, a blank sample that consisted of water and inoculum was also run. 


\section{Analysis}

The compositions of the pretreated materials and samples from the SSF were analyzed on an HPLC instrument (Shimadzu, Kyoto, Japan) that was equipped with a refractive index detector (Shimadzu, Kyoto, Japan). Glucose, xylose, and arabinose were separated using an Aminex HPX-87P column (Bio-Rad, Hercules, CA, USA) at $85^{\circ} \mathrm{C}$ and a flow rate of $0.6 \mathrm{~mL} / \mathrm{min}$ with water as the eluent. Ethanol, acetic acid, lactic acid, glycerol, formic acid, HMF, and furfural were separated on an Aminex HPX-87H column (Bio-Rad, Hercules, CA, USA) at $50{ }^{\circ} \mathrm{C}$ and a flow rate of $0.5 \mathrm{~mL} /$ min using $5 \mathrm{mmol} / \mathrm{L} \mathrm{H}_{2} \mathrm{SO}_{4}$ as the eluent. All samples were passed through a $0.2-\mu \mathrm{m}$ filter before the HPLC analysis.

The volatile solids (VS) content was determined by ashing a sample at $550{ }^{\circ} \mathrm{C}$ for $2 \mathrm{~h}$ after it had been dried at $105^{\circ} \mathrm{C}$ for at least $20 \mathrm{~h}$.

$\mathrm{AD}$ was monitored using a BlueSens system. Methane concentration was measured with an IR sensor (BlueSens BCP-CH4, Germany), and the total volume of gas that was produced was measured on a MilliGascounter (Ritter). Data were collected every $10 \mathrm{~min}$ by BACCom units using the software BACVis. The methane sensor was calibrated weekly.

\section{Modeling}

\section{Simulation tools}

The flow sheeting program Aspen Plus (version 8.2, Aspen Technology Inc., MA, USA) was used to perform the simulations to determine the material and energy balances that were required for further energy and economic evaluations. The NRTL-HOC property method was used in the simulation in all cases, except for the steam cycle, because the Hayden-O'Connell equation of state accounts for dimerization in the vapor phase of organic acids, such as acetic acid. For the steam cycle in the heat and power production stage, the STEAMNBS model was used. The physical property database that was developed by the NREL [44] for components in biofuels, such as lignin and cellulose, was used for the biomass components in the simulations. More recent versions the Aspen Plus models by Wingren et al. [45, 46], Sassner and Zacchi [47], and Joelsson et al. [48] were used to perform the simulations.

Heat integration of the configurations was carried out using Aspen Energy Analyzer (version 8.2) as described [48]. The economic evaluation was performed with the Aspen APEA and the vendors' quotations. Additional information on the Aspen Plus modeling is described elsewhere [49].

\section{Case description}

The 5 experimental SSF configurations-10, 12.5, 15, 17.5, and $20 \%$ WIS-were modeled in Aspen Plus according to their performance in the experimental trials. The first 4 configurations were modeled using the ethanol yield at $96 \mathrm{~h}$ and the corresponding residence time in the SSF for the economic evaluations and were denoted C10-96, C12.596, C15-96, and C17.5-96, respectively. The latter configuration, $20 \%$ WIS, was modeled using the ethanol yield at $192 \mathrm{~h}$ in the simulation; however, the SSF time was set to $96,120,144,168$, and $192 \mathrm{~h}$ in the economic evaluations. The $20 \%$ WIS configuration was termed C20, followed by the time that was set for the SSF (C20-96, C20-120, C20144, C20-168, and C20-192) in the techno-economic evaluation. Various residence times were examined for the $20 \%$ WIS configuration, because the fermentation time in the experiments (192 h) was long and can likely be decreased, for example, by using fed-batch or prehydrolysis steps in the SSF phase. Altogether, 9 basic configurations were studied in the techno-economic evaluations.

The incoming raw material loading was set to 25 tonnes dry wheat straw/h, and the plant was assumed to be operating $8000 \mathrm{~h} /$ year. The plant configuration included the production of pellets, biogas, and electricity as coproducts. The results from the simulations were used to calculate the NPV and energy demand for the processes. An overview of the process as it was modeled is presented in Fig. 9.

\section{Pretreatment}

Steam pretreatment was modeled with an RStoic reactor in Aspen Plus. The reactor was assumed to be a continuous reactor that was injected with 20-bar steam at $200{ }^{\circ} \mathrm{C}$. The steam consumption was increased by $10 \%$ in the model, compared with a unit that was operated adiabatically, to compensate for heat losses and voiding of the reactor. The outgoing material from the reactor was cooled by flashing the material in 2 steps, at 4 and 1 bar. Part of the flashed steam was recirculated and mixed with the feed stream to the reactor to preheat the material. The remaining steam was condensed and cooled to recover heat before being fed to the anaerobic digestion and wastewater treatment unit, because it contained volatile compounds that formed during pretreatment.

The raw material composition, as determined in the experimental trials, was supplemented in the model with $1.8 \%$ acetic acid, based on similar compositions of wheat straw from the literature [18]. The extractives were divided into a group of semivolatile $(8.3 \%)$ and nonvolatile $(5.1 \%)$ components. The recovery factors during pretreatment, as modeled in Aspen Plus, are listed in Table 7, modeled as being present in the solid or liquid fraction of the stream. Some of the volatile components in the liquid fraction in Table 7 were flashed off after leaving the RStoic reactor. The residual carbohydrates, which are not shown in the table, were modeled as degradation products in the liquid fraction. 


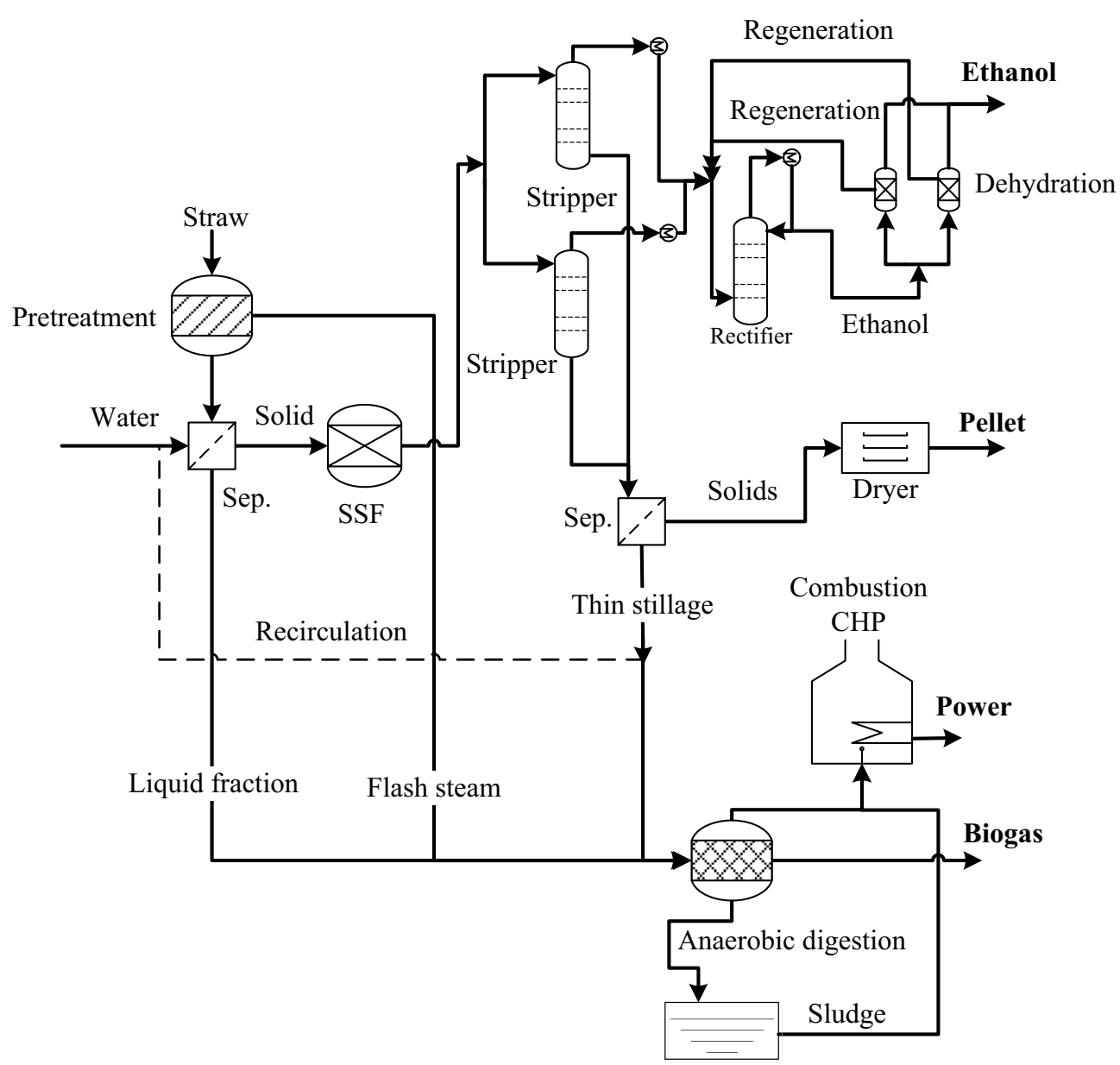

Fig. 9 Process description as modeled in Aspen Plus

Wastewater treatment

Table 7 Recovery factors in Aspen Plus for the pretreatment stage

\begin{tabular}{llll}
\hline Components & $\begin{array}{l}\text { Straw comp. } \\
\text { used in } \\
\text { Aspen Plus (\% } \\
\text { of DM) }\end{array}$ & $\begin{array}{l}\text { Recovery } \\
\text { factors used } \\
\text { in Aspen Plus } \\
\text { WIS (\%) }\end{array}$ & $\begin{array}{l}\text { Recovery factors } \\
\text { used } \\
\text { in Aspen Plus } \\
\text { liquid (\%) }\end{array}$ \\
\hline Glucan & 32.7 & 98 & 2 \\
Xylan & 23.4 & 14 & 55 \\
Arabinan & 4.7 & 21 & 33 \\
Lignin & 22.2 & $88^{\mathrm{a}}$ & 12 \\
Ash & 1.8 & $62^{\mathrm{a}}$ & 38 \\
Acetate & 1.8 & 10 & 90 \\
Extractives & & & 100 \\
Semivol & 8.3 & 0 & 100 \\
Nonvol & 5.1 & 0 & \\
\hline
\end{tabular}

a $12 \%$ of the lignin and $38 \%$ of the ash were converted to soluble lignin and soluble ash, respectively, in the model, but they were still modeled, because they were present in the solid fraction

\section{SSF}

A wash and separation step was included in the model of the pretreated material before it was diluted with water to attain the proper WIS concentration for the SSF. The wash volume was set to 1.5 times the original liquid volume in the pretreated material before filtration. The SSF was then modeled with RStoic reactors in Aspen Plus. Part of the liquid fraction from the separation step was used for the yeast cultivation step. The liquid was supplemented with molasses to set the sugar concentration that was required to produce biomass that corresponded to a yeast concentration of $3 \mathrm{~g} / \mathrm{L}$ in the SSF. The yeast production yield was set to $0.5 \mathrm{~g}$ biomass $/ \mathrm{g}$ fermentable sugar.

The glucose-to-ethanol conversions for the various configurations in the SSF were based on the results obtained in the experimental part of the study. For C10-96, C12.5-96, C15-96, and C17.5-96, the 
conversion factors at $96 \mathrm{~h}$ were used, whereas the ethanol yield in the SSF after $192 \mathrm{~h}$ was applied for C20-96 to C20-192. The enzymes were added at the quantities that were required to obtain an activity of $10 \mathrm{FPU} / \mathrm{g}$ WIS. The final ethanol concentration in the fermentation broth in the simulations varied between 2.8 and $5.7 \mathrm{wt} \%$. The residence time in the SSF was set to $96 \mathrm{~h}$ (except for $20 \%$ WIS, for which the time ranged from 96 to $192 \mathrm{~h}$ ), and the emptying, cleaning, and refilling times were set to $12 \mathrm{~h}$ in all cases. In the experimental study, the solids were separated before the distillation step to facilitate the evaporation of ethanol, but in the simulations, the separation was modeled to occur after the distillation step.

\section{Distillation}

Two parallel 25-stage, high-pressure stripper columns, followed by a 35-stage, low-pressure rectifying column, were used in the simulations to concentrate the ethanol in the fermentation broth to $92.5 \mathrm{wt} \%$. A top-stage pressure of 1.25 and 3 bar, respectively, was used for the stripper columns versus 0.3 bar in the rectifying column. The Murphree efficiency was set to $50 \%$ in the stripper columns and $75 \%$ in the rectifying column. The feed stream to the stripper columns was split such that the energy from the condensing overhead vapor from the 3-bar stripper column could be used to supply the 1.25-bar column with heat. Most of the energy that was released when the overhead vapor was condensed from the 1.25bar stripper was used to heat the rectifying column.

Two molecular sieve dehydration columns were used to concentrate the ethanol overhead vapor from the rectifying column to $99.5 \%$, before the ethanol was cooled and stored. The rectifying column was equipped with a partial-vapor condenser, and the vapor was superheated before entering the sieves. The regeneration stream from the molecular sieve stage was mixed with the streams from the stripper columns before being fed to the rectifier. The ethanol concentration in the feed stream to the rectifying column and the mass reflux ratio varied from 27 and $44 \mathrm{wt} \%$ and from 1.33 and 1.37, respectively.

\section{Solids separation of stillage}

The stillage from the stripper column, containing between 8 and $15 \mathrm{wt} \% \mathrm{DM}$, was first cooled to $80{ }^{\circ} \mathrm{C}$ and then filtered to obtain a wet cake of solid particles, with a DM content of $45 \mathrm{wt} \%$, and thin stillage with a DM content of between 3 and $5 \mathrm{wt} \%$. The solid particle retention rate was set to $95 \%$ for the filter unit in the model. Part of the thin stillage was then recirculated and used as a dilution medium in the SSF stage. The remainder of the thin stillage was sent to anaerobic digestion. A maximum of $40 \%$ of the water in the fermentation was assumed to have originated from the thin stillage. The wet cake fraction was split in 2 streams such that only the portion that was not required for heat production was fed to the dryer, whereas the rest was transferred to the boiler unit for heat generation.

\section{Drying}

A steam dryer was used to dry the solid fraction from the filtration of the stillage. The incoming material was preheated from 80 to $140{ }^{\circ} \mathrm{C}$ before entering the dryer, in which it was dried with 4-bar superheated steam at $200{ }^{\circ} \mathrm{C}$. Ninety percent of the outgoing steam from the dryer was superheated again to $200{ }^{\circ} \mathrm{C}$ and recirculated to the dryer. The remaining steam was condensed and transferred to the anaerobic digestion stage. The dried solids, which were assumed to be pelletized, had a DM content of $88 \%$.

\section{Anaerobic digestion and wastewater treatment}

Biogas was produced from the liquid fraction after pretreatment, the stillage from the rectifier, and the thin stillage from the stripper columns, with the condensed steam from the dryer and pretreatment step. An average value of biogas production was used in the simulations, based on an assumed reduction in chemical oxygen demand (COD) of the substrate. The fractional conversion factor that was used to calculate the decrease in COD was set to $90 \%$ for easily digested material, such as organic acids and monomeric sugars, whereas material that was assumed to require additional hydrolysis, such as polysaccharides and degradation products from the pretreatment step, were assigned a fractional conversion of $50 \%$ [50]. For lignin and other materials that are difficult to degrade, the fractional conversion was set to 0 [51].

The ratio of the potential reduction in COD was then multiplied with a theoretical methane production value of $0.25 \mathrm{~kg}$ methane $/ \mathrm{kg}$ COD [16]. The outgoing biogas stream composition was set to $50 \%$ methane, $46 \%$ carbon dioxide, and $4 \%$ water, and the sludge that was generated in the anaerobic digestion stage was incinerated. The economic evaluations for the anaerobic digestion step, with the subsequent aerobic wastewater treatment step, were based on estimations by PURAC $\mathrm{AB}$, Lund, Sweden, in which $25 \mathrm{wt} \%$ ammonia and 50 wt\% phosphoric acid were added to cover the nitrogen and phosphorous requirements, corresponding to $12.5 \mathrm{~kg}$ nitrogen $/ \mathrm{h}$ and $2.1 \mathrm{~kg}$ phosphorous $/ \mathrm{h}$. The residence time in the anaerobic digestion was assumed to be 20 days, and the subsequent aerobic step was assumed to be 4 days. The sludge that was produced in the anaerobic digestion corresponded to $0.03 \mathrm{~kg} / \mathrm{kg}$ COD. 


\section{Energy supply}

The electricity and heat that were required in the process were assumed to be supplied by a co-located combined heat and power (CHP) plant. The plant was equipped with a high-pressure boiler that produced superheated steam at 90 bar and $470{ }^{\circ} \mathrm{C}$. The boiler was fueled by solid residues from the distillation and sludge from the anaerobic digestion stage. Electricity was generated by a steam turbine system. High-temperature steam, withdrawn at 20 bar, was used to supply the pretreatment unit and the dryer with heat. Four-bar steam was used for the remainder of the process. The isentropic and mechanical efficiencies for the turbines were set to 90 and $97 \%$, respectively. The electricity demand of the plants was estimated using values from the manufacturers' quotations and calculations in APEA. If more or less electricity was produced than required in the plant, the surplus or deficit was assumed to be sold to or bought from the grid.

The energy input and output for the plant were calculated, based on the lower heating value (LHV) of the materials. The LHVs were obtained from calculations in Aspen Plus on the heat of combustion for the various materials, except for ethanol and methane, for which values of 26.7 and $50 \mathrm{MJ} / \mathrm{kg}$, drawn from the literature, were used, respectively. The LHVs for the ingoing materials were $19.6 \mathrm{MJ} / \mathrm{kg} \mathrm{DM}(89 \% \mathrm{DM})$ for straw, $6.98 \mathrm{MJ} / \mathrm{kg}$ $\mathrm{DM}$ for molasses, and $1.2 \mathrm{MJ} / \mathrm{kg} \mathrm{DM}$ for the enzymes. The LHV for the pellets that had a DM content of $88 \%$ was $21.0 \mathrm{MJ} / \mathrm{kg} \mathrm{DM}$. The energy requirement to harvest and transport the straw an average distance of $50 \mathrm{~km}$ was also included in the calculation and was set to $0.025 \mathrm{MJ} / \mathrm{MJ}$ dry biomass [52]. The energy efficiency of the products was calculated as the ratio of the energy flow (in MW) of the products to the ingoing energy flow, as shown in Eq. 1.

$$
\begin{aligned}
\text { Energy efficiency }= & \text { Product } /(\text { Raw material } \\
& + \text { Molasses }+ \text { Enzyme } \\
& + \text { Harvest and Transportation })
\end{aligned}
$$

\section{Cost calculations}

The energy and mass balances from Aspen Plus were imported into APEA and Excel to size the equipment and estimate the capital and operational costs. Vendors' quotations were used to estimate the costs for the boiler, dryer, and pelletizing equipment; molecular sieves; filter presses; and the anaerobic digestion and pretreatment units. The chemical engineering plant cost index was used to update the prices to 2012 values. The construction time of the plant was set to 1 year, and the plant was assumed to be the Nth plant constructed for a plant located in Sweden, meaning that the technology and construction of the plant should be considered established concepts. The exchange rate was $1 \mathrm{EUR}=9$ SEK.
The remaining cost for the equipment and installation, as well as the construction, electricity installation, instrumentation, land, engineering, and fees that were associated with the construction of the plant, were estimated in APEA. The operational cost item was based on Swedish conditions and consisted of fixed- and variable costs. The fixed operational cost comprised the costs for insurance, maintenance, working capital, and labor. The insurance cost was set to $1 \%$ of the capital cost, and the maintenance cost was fixed to $2 \%$. The annual working capital cost was assumed to correspond to an interest rate of $11 \%$ per recommendations in the literature [53]. The plant was assumed to be operated by 30 persons. The variable operational cost comprised the cost of raw materials, chemicals, and utilities. The operational costs and prices of products are listed in Table 8 . The costs and prices are average values that were determined after consulting open source references and through personal communication with companies. The cost of the enzymes was set to 3.0 EUR per million FPU.

The final capital and operation costs and the revenues of the products were entered into an Excel spreadsheet,

\begin{tabular}{|c|c|c|}
\hline & Cost/unit & Units \\
\hline \multicolumn{3}{|l|}{ Input } \\
\hline Wheat straw ${ }^{a}$ & 0.09 & EUR/kg DM \\
\hline Enzyme & 3.00 & $\mathrm{EUR} / 10^{6} \mathrm{FPU}$ \\
\hline Acetic acid ${ }^{b}$ & 0.17 & $\mathrm{EUR} / \mathrm{kg}$ \\
\hline Phosphoric acid $(50 \mathrm{wt} \%)^{\mathrm{b}}$ & 0.56 & EUR/kg \\
\hline$\left(\mathrm{NH}_{4}\right)_{2} \mathrm{HPO}_{4}^{\mathrm{b}}$ & 0.67 & EUR/kg \\
\hline $\mathrm{MgCl}_{2}^{\mathrm{b}}$ & 0.17 & EUR/kg \\
\hline Ammonia $(25 w t \%)^{c}$ & 0.22 & EUR/kg \\
\hline Antifoam $^{d}$ & 2.22 & $\mathrm{EUR} / \mathrm{kg}$ \\
\hline \multicolumn{3}{|l|}{ Utilities } \\
\hline Process water ${ }^{\mathrm{e}}$ & 0.16 & EUR/kg \\
\hline Cooling water ${ }^{\mathrm{e}}$ & 0.02 & EUR/kg \\
\hline \multicolumn{3}{|l|}{ Products } \\
\hline Ethanol & 0.67 & EUR/L \\
\hline Biogas, raw ${ }^{f}$ & 33.00 & EUR/MWh \\
\hline Biogas, upgraded to vehicle fuel quality ${ }^{f}$ & 67.00 & EUR/MWh \\
\hline Electricity (spot and certificate price) ${ }^{g}$ & 0.67 & EUR/MWh \\
\hline Carbon dioxide ${ }^{h}$ & 0.003 & EUR/kg \\
\hline
\end{tabular}

Table 8 Variable operational costs and prices of products used in the calculations

\begin{tabular}{ll}
\hline a & Ref. [54] \\
${ }^{\text {b }}$ & Ref. [55] \\
${ }^{c}$ & Ref. [56] \\
${ }^{\text {d }}$ Ref. [57] \\
${ }^{\text {e }}$ Ref. [58] \\
${ }^{\text {f }}$ Ref. [59] \\
${ }^{g}$ Ref. [34] \\
${ }^{\text {h }}$ Ref. [60]
\end{tabular} 
and the NPV and minimal ethanol selling price (MESP) were then calculated using Eq. 2.

$$
N P V=I_{0}+\sum_{n=1}^{n} \frac{C F_{n}}{\left(1+r_{d}\right)^{n}}
$$

The investment lifetime (n) was set to 20 years, and the discount rate $\left(\mathrm{r}_{\mathrm{d}}\right)$ was set to $11 \%$. The capital cost was denoted $\mathrm{I}_{0}$, and the operational cost (also called cash flow) was termed CF in Eq. 2. The MESP was calculated by setting the NPV to 0 . The calculated NPVs and MESPs are not absolute values but instead are used to compare and evaluate the various cases in the study. If financial decisions are to be made, more thorough examination and forecasting must be performed.

\section{Sensitivity analysis and process modification}

Sensitivity analyses were conducted to determine the effects on the NPV when the economic assumptions regarding the discount rate and price of biogas were changed and corporate tax was imposed. The discount rate was lowered from 11 to $5 \%$, which can reflect the return on an investment in a risk-free asset, and the NPV and MESP were calculated for the configurations. Two taxation rates were imposed on the configurations at a $5 \%$ discount rate. The taxation rates were set to 20 and $30 \%$ and straight-line depreciation of 10 years was used when corporate tax was imposed. The price of raw biogas doubled from 33 to $67 \mathrm{EUR} / \mathrm{MWh}$ at an $11 \%$ discount rate, and the NPV was calculated.

Two modifications to the process were made to examine the NPV and MESP. First, the biogas was upgraded to vehicle fuel quality by pressure swing absorption in all configurations and thus assigned a higher price (67 EUR/ MWh from Table 8). The investment cost for the upgrade to vehicle fuel quality, which was added to the capital cost, was based on the assumption that the cost was going to be 1500 EUR, multiplied by the volume of biogas that was produced per hour $\left(\mathrm{Nm}^{3} / \mathrm{h}\right)$, and that the electricity demand would increase with $0.3 \mathrm{kWh} / \mathrm{Nm}^{3}$ raw biogas that is upgraded to vehicle fuel quality [59].

The second modification was performed only for configuration C17.5-96, which was altered to include fermentation of xylose to ethanol and denoted C17.5-96X. No separation of the material after pretreatment, except for the liquid portion that was subtracted for use in the cultivation, or wash was then simulated. The conversion of xylose to ethanol in the SSF stage was set to 0.9, and the cultivated yeast was assumed to co-ferment xylose and glucose. A license cost of $0.05 \mathrm{EUR} / \mathrm{L}$ ethanol was set for the yeast.

\section{Abbreviations}

APEA: Aspen Process Economic Analyzer; COD: chemical oxygen demand; CHP: combined heat and power; DM: dry matter; FPU: filter paper units; IRR: internal rate of return; LHV: lower heating value; MESP: minimum ethanol selling price; NREL: National Renewable Energy Laboratory; NPV: net present value; SSF: simultaneous saccharification and fermentation; WIS: water-insoluble solids.

\section{Authors' contributions}

EJ participated in the interpretation of the experimental results and the design of the simulations, carried out the simulations, and wrote part of the manuscript. DD performed the experiments and revised the manuscript. KK interpreted the experimental results, participated in the design of the simulation study, and wrote part of the manuscript. MG participated in the design of experiments, contributed during the preparation of the manuscript, and revised the manuscript. OW participated in the design of the simulation study and the interpretation of the results and revised the manuscript. All authors read and approved the manuscript.

\section{Acknowledgements}

The Swedish Energy Agency is gratefully acknowledged for its financial support.

\section{Competing interests}

The authors declare that they have no competing interests.

Received: 15 February 2016 Accepted: 2 August 2016

Published online: 16 August 2016

\section{References}

1. Erdei B (2013) Development of integrated cellulose- and starch-based ethanol production and process design for improved xylose conversion [Doctoral Thesis]. Lund University, Lund

2. Madhavan A, Srivastava A, Kondo A, Bisaria VS (2012) Bioconversion of lignocellulose-derived sugars to ethanol by engineered Saccharomyces cerevisiae. Crit Rev Biotechnol 32(1):22-48

3. Kim SR, Park YC, Jin YS, Seo JH (2013) Strain engineering of Saccharomyces cerevisiae for enhanced xylose metabolism. Biotechnol Adv 31(6):851-861

4. Hahn-Hägerdal B, Wahlbom CF, Gárdonyi M, van Zyl WH, Cordero Otero RR, Jönsson $\sqcup$ (2001) Metabolic engineering of Saccharomyces cerevisiae for xylose utilization. Adv Biochem Eng Biotechnol 73:53-84

5. Chu BCH, Lee H (2007) Genetic improvement of Saccharomyces cerevisiae for xylose fermentation. Biotechnol Adv 25(5):425-441

6. Nevoigt $E$ (2008) Progress in metabolic engineering of Saccharomyces cerevisiae. Microbiol Mol Biol R 72(3):379-412

7. Gunaseelan VN (1997) Anaerobic digestion of biomass for methane production: a review. Biomass Bioenergy 13(1-2):83-114

8. Fuchs $\mathrm{G}$, Boll M, Heider J (2011) Microbial degradation of aromatic compounds — from one strategy to four. Nat Rev Microbiol 9(11):803-816

9. Evans WC, Fuchs G (1988) Anaerobic degradation of aromatic compounds. Annu Rev Microbiol 42:289-317

10. Vivekanand V, Olsen EF, Eijsink VGH, Horn SJ (2013) Effect of different steam explosion conditions on methane potential and enzymatic saccharification of birch. Bioresour Technol 127:343-349

11. Kaparaju P, Serrano M, Thomsen AB, Kongjan P, Angelidaki I (2009) Bioethanol, biohydrogen and biogas production from wheat straw in a biorefinery concept. Bioresour Technol 100(9):2562-2568

12. Rabelo SC, Carrere H, Maciel Filho R, Costa AC (2011) Production of bioethanol, methane and heat from sugarcane bagasse in a biorefinery concept. Bioresour Technol 102(17):7887-7895

13. Larsen J, Haven MT, Thirup L (2012) Inbicon makes lignocellulosic ethanol a commercial reality. Biomass Bioenergy 46:36-45

14. Luo G, Talebnia F, Karakashev D, Xie L, Zhou Q, Angelidaki I (2011) Enhanced bioenergy recovery from rapeseed plant in a biorefinery concept. Bioresour Technol 102(2):1433-1439 
15. Kaparaju P, Serrano M, Angelidaki I (2010) Optimization of biogas production from wheat straw stillage in UASB reactor. Appl Energy 87(12):3779-3783

16. Kreuger E, Sipos B, Zacchi G, Svensson SE, Björnsson L (2011) Bioconversion of industrial hemp to ethanol and methane: the benefits of steam pretreatment and co-production. Bioresour Technol 102(3):3457-3465

17. Bauer A, Bösch P, Friedl A, Amon T (2009) Analysis of methane potentials of steam-exploded wheat straw and estimation of energy yields of combined ethanol and methane production. J Biotechnol 142(1):50-55

18. Linde M, Jakobsson E-L, Galbe M, Zacchi G (2008) Steam pretreatment of dilute $\mathrm{H}_{2} \mathrm{SO}_{4}$-impregnated wheat straw and SSF with low yeast and enzyme loadings for bioethanol production. Biomass Bioenergy 32(4):326-332

19. Bondesson PM, Galbe M, Zacchi G (2014) Comparison of energy potentials from combined ethanol and methane production using steam-pretreated corn stover impregnated with acetic acid. Biomass Bioenergy 67:413-424

20. Koppram R, Tomás-Pejó E, Xiros C, Olsson L (2014) Lignocellulosic ethanol production at high-gravity: challenges and perspectives. Trends Biotechnol 32(1):46-53

21. Macrelli S, Galbe M, Wallberg O (2014) Effects of production and market factors on ethanol profitability for an integrated first and second generation ethanol plant using the whole sugarcane as feedstock. Biotechnol Biofuels 7(1):26

22. Dias MOS, Junqueira TL, Cavalett O, Pavanello LG, Cunha MP, Jesus CDF et al (2013) Biorefineries for the production of first and second generation ethanol and electricity from sugarcane. Appl Energy 109:72-78

23. Martín M, Grossmann IE (2012) Energy optimization of bioethanol production via hydrolysis of switchgrass. AIChE J 58(5):1538-1549

24. Tao L, Aden A, Elander RT, Pallapolu VR, Lee YY, Garlock RJ et al (2011) Process and technoeconomic analysis of leading pretreatment technologies for lignocellulosic ethanol production using switchgrass. Bioresour Technol 102(24):11105-11114

25. Stephen JD, Mabee WE, Saddler JN (2013) Lignocellulosic ethanol production from woody biomass: the impact of facility siting on competitiveness. Energy Policy 59:329-340

26. Stephen JD, Mabee WE, Saddler JN (2012) Will second-generation ethanol be able to compete with first-generation ethanol? Opportunities for cost reduction. Biofuels Bioprod Biorefin 6(2):159-176

27. Piccolo C, Bezzo F (2009) A techno-economic comparison between two technologies for bioethanol production from lignocellulose. Biomass Bioenergy 33(3):478-491

28. Kazi FK, Fortman JA, Anex RP, Hsu DD, Aden A, Dutta A et al (2010) Techno-economic comparison of process technologies for biochemical ethanol production from corn stover. Fuel 89(Supplement 1):S20-S28

29. Čuček L, Martín M, Grossmann IE, Kravanja Z (2011) Energy, water and process technologies integration for the simultaneous production of ethano and food from the entire corn plant. Comput Aided Chem Eng 29:2004-2008

30. Aden A, Foust T (2009) Techno economic analysis of the dilute sulfuric acid and enzymatic hydrolysis process for the conversion of corn stover to ethanol. Cellulose 16(4):535-545

31. Modarresi A, Kravanja P, Friedl A (2012) Pinch and exergy analysis of lignocellulosic ethanol, biomethane, heat and power production from straw. Appl Therm Eng 43:20-28

32. Kravanja P, Modarresi A, Friedl A (2013) Heat integration of biochemical ethanol production from straw-a case study. Appl Energy 102:32-43

33. Lassmann T, Kravanja P, Friedl A (2014) Simulation of the downstream processing in the ethanol production from lignocellulosic biomass with ASPEN Plus ${ }^{\circledR}$ and IPSEpro. Energy Sustain Soc 4(1):1-7

34. Ekman A, Wallberg O, Joelsson E, Börjesson P (2013) Possibilities for sustainable biorefineries based on agricultural residues - a case study of potential straw-based ethanol production in Sweden. Appl Energy 102:299-308

35. Kravanja P, Könighofer K, Canella L, Jungmeier G, Friedl A (2012) Perspectives for the production of bioethanol from wood and straw in Austria: technical, economic, and ecological aspects. Clean Technol Environ Policy 14(3):411-425

36. Wang Z, Lv Z, Du J, Mo C, Yang X, Tian S (2014) Combined process for ethanol fermentation at high-solids loading and biogas digestion from unwashed steam-exploded corn stover. Bioresour Technol 166:282-287

37. Cannella D, Jørgensen H (2014) Do new cellulolytic enzyme preparations affect the industrial strategies for high solids lignocellulosic ethanol production? Biotechnol Bioeng 111(1):59-68
38. Macrelli S (2014) Ethanol from sugarcane lignocellulosic residues opportunities for process improvement and production cost reduction [Doctoral Thesis]. Lund University, Lund

39. Zhang J, Bao J (2012) A modified method for calculating practical ethanol yield at high lignocellulosic solids content and high ethanol titer. Bioresour Technol 116:74-79

40. Galbe M, Sassner P, Wingren A, Zacchi G (2007) Process engineering economics of bioethanol production. Biofuels 108:303-327

41. Sluiter A, Hames B, Ruiz R, Scarlata C, Sluiter J, Templeton D, Crocker D (2008) Determination of structural carbohydrates and lignin in biomass. Laboratory Analytical Procedure, National Renewable Energy Laboratory, Golden, Colorado, USA, Report No. TP-510-42618

42. Sluiter A, Hames B, Ruiz R, Scarlata C, Sluiter J, Templeton D, Crocker D (2008) Determination of sugars, byproducts, and degradation products in liquid fraction process samples. Laboratory Analytical Procedure, National Renewable Energy Laboratory, Golden, Colorado, USA, Report No. TP-510-42623

43. Taherzadeh MJ, Liden G, Gustafsson L, Niklasson C (1996) The effects of pantothenate deficiency and acetate addition on anaerobic batch fermentation of glucose by Saccharomyces cerevisiae. Appl Microbiol Biotechnol 46:176-182

44. Wooley RJ, Putsche V (1996) Development of an Aspen Plus physical property database for biofuels components. Golden. Document No. MA 425-20685

45. Wingren A, Söderström J, Galbe M, Zacchi G (2004) Process considerations and economic evaluation of two-step steam pretreatment for production of fuel ethanol from softwood. Biotechnol Progr 20(5):1421-1429

46. Wingren A, Galbe M, Zacchi G (2008) Energy considerations for a SSFbased softwood ethanol plant. Bioresour Technol 99(7):2121-2131

47. Sassner P, Zacchi G (2008) Integration options for high energy efficiency and improved economics in a wood-to-ethanol process. Biotechnol Biofuels 1(1):4

48. Joelsson E, Galbe M, Wallberg O (2014) Heat integration of combined 1st and 2 nd generation ethanol production from wheat kernels and wheat straw. Sustain Chem Process 2(1):1-20

49. Joelsson E, Wallberg O, Börjesson P (2015) Integration potential, resource efficiency and cost of forest-fuel-based biorefineries. Comput Chem Eng 82:240-258

50. Labatut RA (2012) Anaerobic biodegradability of complex substrates: performance and stability at mesophilic and thermophilic conditions [Doctoral Thesis]. Cornell University, Ithaca

51. Triolo JM, Sommer SG, Moller HB, Weisbjerg MR, Jiang XY (2011) A new algorithm to characterize biodegradability of biomass during anaerobic digestion: influence of lignin concentration on methane production potential. Bioresour Technol 102:9395-9402

52. Börjesson P, Tufvesson LM (2011) Agricultural crop-based biofuelsresource efficiency and environmental performance including direct land use changes. J Clean Prod 19(2-3):108-120

53. Peters MS, Timmerhaus KD (1980) Plant design and economics for chemical engineers, 3rd edn. McGraw-Hill, New York

54. Halm som Biogassubstrat. Johansson L-G (2012) http://www.jti.se/uploads/ ovriga/Temabiogas2012_LarsGunnar.Johansson.pdf. Accessed 14 Jul 2012

55. Business Chemical (2012) Market price. Chemical Business. 26(8):70-71

56. US Producer Price Index: Chemicals and Allied Products: Synthetic Ammonia, Nitric Acid, Ammonium Compounds. YChart (2012) https:// www.ycharts.com/indicators/us_producer_price_index_chemicals_and_ allied_products_synthetic_ammonia_nitric_acid_ammonium_compounds. Accessed 28 May 2015

57. Yantai Thinking Finechem Technology Co. L (2015) http://www.thinkingchem.en.alibaba.com/productgrouplist-221792649/This_298_Fermentation_Defoamer.html. Accessed 28 May 2015

58. Seider WD, Seader JD, Lewin DR, Widagdo S (2010) Product and process design principles-synthesis, analysis, and evaluation, 3rd edn. Wiley, Hoboken

59. Bauer F, Hulteberg C, Persson Tobias, Daniel T (2013) Biogas upgrading review of commercial technologies (biogasuppgradering-Granskning av kommersiella tekniker. http://www.sgc.se: 2013 Report No. SGC Rapport. p 270

60. Wilson R, Luckow P, Biewald B, Ackerman F, Hausman E (2012) Carbon dioxide price forecast. Synapse Energy Economics, Inc, Cambridge 